\title{
Revision of the Paridris nephta species group (Hymenoptera, Platygastroidea, Platygastridae)
}

\author{
Elijah J. Talamas ${ }^{1, \dagger}$, Lubomír Masner ${ }^{2, \ddagger}$, Norman F. Johnson ${ }^{3, \S}$ \\ I Department of Entomology, The Ohio State University, 1315 Kinnear Road, Columbus, Ohio 43212, U.S.A. \\ 2 Agriculture and Agri-Food Canada, K. W. Neatby Building, Ottawa, Ontario K1A 0C6, Canada 3 Department \\ of Evolution, Ecology and Organismal Biology, The Ohio State University, 1315 Kinnear Road, Columbus, Ohio \\ 43212, U.S.A. \\ † urn:lsid:zoobank.org:author:19124B60-4D11-46AF-ADBF-E48A9988B102 \\ $\ddagger$ urn:lsid:zoobank.org:author:F1505310-F606-4F6C-A1DF-74B9A0055B2E \\ § urn:lsid:zoobank.org:author:3508C4FF-F027-445F-8417-90AB4AB8F30D \\ Corresponding author: Elijah J. Talamas (talamas.1@osu.edu)
}

Academic editor: Michael Sharkey| Received 26 May 2011 | Accepted 1 August 2011 | Published 5 October 2011

urn:lsid:zoobank.org:pub:BCD3BD6E-5E29-447F-AEB6-176C19EEF3E8

Citation: Talamas EJ, Masner L, Johnson NF (2011) Revision of the Paridris nephta species group (Hymenoptera, Platygastroidea, Platygastridae). ZooKeys 133: 49-94 doi: 10.3897/zookeys.133.1613

\begin{abstract}
The Paridris nephta group is revised (Hymenoptera: Platygastridae). Fifteen species are described, 14 of which are new: Paridris atrox Talamas, sp. n. (Yunnan Province, China), P. bunun Talamas, sp. n. (Taiwan), P. ferus Talamas, sp. n. (Thailand), P. kagemono Talamas, sp. n. (Japan), P. minator Talamas, sp. n. (Laos, Thailand), P. mystax Talamas, sp. n. (Laos, Thailand), P. nephta (Kozlov) (Japan, North Korea, South Korea, Far Eastern Russia), P. nilaka Talamas, sp. n. (Thailand), P. reptilis Talamas, sp. n. (Taiwan), P. rugulosus Talamas, sp. n. (Laos, Vietnam), P. solaris Talamas, sp. n. (Laos, Thailand, Vietnam), P. teres Talamas, sp. n. (Vietnam), P. toketoki Talamas, sp. n. (Taiwan), P. verrucosus Talamas, sp. n. (Guangdong Province, China), P. yak Talamas, sp. n. (Thailand).
\end{abstract}

\section{Keywords}

Egg-parasitoid, Platygastroidea, key, species description, taxonomic revision

Copyright Elijah J.Talamas et al. This is an open access article distributed under the terms of the Creative Commons Attribution License, which permits unrestricted use, distribution, and reproduction in any medium, provided the original author and source are credited. 


\section{Introduction}

In 1978, M. Kozlov described a new genus of scelionine wasps based on material from the Russian Far East, with Tuora nephta Kozlov as its sole species. No major taxonomic changes occurred in this group until Kononova and Kozlov (2008) treated Tuora as a junior synonym of Paridris Kieffer, a huge cosmopolitan group. Examination of material from East and Southeast Asia has brought to light many new species that are morphologically close to Paridris nephta, constituting a rather homogenous group that may be readily separated from the remainder of Paridris.

The goals of this paper are to define the Paridris nephta group and describe its species. This work is conducted as part of the Platygastroidea Planetary Biodiversity Inventory and represents a step toward revision of Scelionini sensu lato and resolution of the relationships between its constituent genera. The contributions of the authors are as follows: E.J. Talamas: character definition, species group concept development, species concept development, imaging, key development, manuscript preparation; N.F. Johnson: species concept development, key development, manuscript preparation; L. Masner: species group concept development, manuscript preparation.

\section{Materials and methods}

Specimens: This work is based upon specimens deposited in the following collections, with abbreviations used in the text: CNCI, Canadian National Collection of Insects, Ottawa, Canada ${ }^{1}$; IEBR, Institute of Ecology and Biolgical Resources, Hanoi, Vietnam $^{2}$; IZCAS, Chinese Academy of Sciences, Institute of Zoology, Beijing, China3; OSUC, C.A. Triplehorn Insect Collection, Columbus, $\mathrm{OH}^{4}$; QSBG, Queen Sirikit Botanic Garden, Chiang Mai, Thailand'; ROME, Royal Ontario Museum, Ontario, Canada $^{6} ; \mathrm{RMNH}$, Leiden Nationaal Natuurhistorische Museum, Netherlands ${ }^{7}$.

Morphology: Abbreviations and morphological terms used in text: A1, A2, ... A12: antennomere 1, 2, .. 12; claval formula: distribution of the multiporous basiconic sensilla on the underside of apical antennomeres of the female, with the antennomere interval specified followed by the number of sensilla per segment (Bin 1981); palpal formula: number of maxillary and labial palpal segments, respectively; S1, S2, ... S6: metasomal mediosternite 1, 2, .. 6; T1, T2, ... T7: metasomal mediotergite 1, 2, ... 7.; posterior vertex: area between the posterior ocelli and the occipital carina. Morphological terminology largely follows Mikó et al. 2007; the following are illustrated and labeled to facilitate their use.

Axillular carina (axc: Figs 15-16)

Epomial carina (epc; Fig. 7)

Lateral ocellus (loc; Figs 10-11)

Metapleural sulcus (mtps; Fig. 36)

Paracoxal sulcus (pcxs; Fig. 36) 
Transverse carina of T2 (trc; Fig. 12)

Transverse pronotal carina (tpc; Fig. 7)

Morphological terms used in this revision were matched to the Hymenoptera Anatomy Ontology (HAO, Yoder et al. 2010) (Appendix I). Identifiers (URIs) in the format http://purl.obolibrary.org/obo/HAO_XXXXXXX represent anatomical concepts in HAO version http://purl.obolibrary.org/obo/hao/2011-05-18/hao.owl. They are provided to enable readers to confirm their understanding of the anatomical structures being referenced. To find out more about a given structure, including, images, references, and other metadata, use the identifier as a web-link, or use the HAO:XXXXXXX (note colon replaces underscore) as a search term at http://glossary. hymao.org. Notable changes in term usage from a previous taxonomic work (Talamas et al. 2011) are given in Appendix I.

The description of surface sculpture is presented in two formats. Areas of the exoskeleton in which the sculptural elements are inseparable are described simply as "sculpture". For areas in which the sculptural elements vary independently, sculpture is divided into three categories: punctation: round depressions associated with setae; macrosculpture: raised or sunken patterns of texture that are oriented linearly or radially with respect to punctation or the axes of the body; microsculpture: unoriented, very fine wrinkles or pustulations that occur on, in, or between elements of macrosculpture and punctation.

Information Management: The locality data reported for primary types are not literal transcriptions of the labels: some abbreviations are expanded; additional data from the collectors are also included. The holotypes should be unambiguously identifiable by means of the unique identifier or the red holotype label. The numbers prefixed with "OSUC" and "CASENT" are unique identifiers for the individual specimens (note the blank space after the acronyms). Details on the data associated with these specimens may be accessed at the following link, purl.oclc.org/NET/hymenoptera/ hol, and entering the identifier in the form. This monograph also features simultaneous publication and distribution of taxonomic and occurrence records through the Global Biodiversity Information Facility (GBIF) using DarwinCore Archives as in Talamas et al. (2011). All new species have been prospectively registered with Zoobank (Polaszek et al. 2005) and other taxonomic names have been retrospectively registered therein. All names are also registered in the Hymenoptera Name Server (hns.osu.edu). Life sciences identifiers, lsids, may be resolved at the URLs specified in the footnotes or at lsid.tdwg.org.

Cybertools: The species descriptions are generated by a database application, vSysLab (purl.oclc.org/NET/hymenoptera/vSysLab), designed to facilitate the generation of taxon by character data matrices, to integrate these with the existing taxonomic and specimen-level database, and to export the data both as text and as input files for other applications. The output is in the format of "Character: Character state(s)."

Imaging: Images were produced using Combine ZP and AutoMontage extendedfocus software. The individual images are archived at the image database at The Ohio 
State University (purl.oclc.org/NET/hymenoptera/specimage) and with MorphBank (www.morphbank.net). The latter also contains collections of images organized by plate.

Species Concept: For the purpose of this revision, species are defined as taxa diagnosable by putative autapomorphies or a unique combination of fixed character states.

\section{Comments on Paridris Kieffer}

The genus Idris was described by Arnold Förster in 1856, and the name has been used as the root for a number of generic names in Platygastroidea. Wheeler (1935) proposed that it would be a useful root for names within the Formicidae, relieving the stress on roots such as -myrmex and -myrma. According to Wheeler, the name is a substantive noun, derived from classical Greek, meaning "the knowing or provident one." As such, it may be either masculine or feminine in grammatical gender. While workers in Platygastroidea have treated the name and its derivatives as masculine, myrmecologists have used names with this root as feminine nouns. Here, we continue our tradition and use Paridris as a masculine noun.

The Nearctic Paridris brevipennis Fouts has one documented host association with Gryllus pennsylvanicus Burmeister (label data of a specimen in the USNM reported by Masner and Muesebeck, 1968). Based on this information, we speculate that the species of the P. nephta group are also parasitoids of gryllid eggs.

With the exception of Masner (1976), previous workers treated Paridris within only a restricted geographical context (Mani and Sharma 1982, Galloway and Austin 1984, Kozlov and Kononova 1985, Kozlov and Kononova 1990, Kononova and Petrov 2000, Lê 2000, Mineo 2005, Rajmohana 2006, Kononova and Kozlov 2008). Perhaps unsurprisingly, the characters they used for identification of the genus are insufficient when the world fauna is considered: the length of R1 (postmarginal vein) is variable; the shape of the metascutellum is highly variable, and in females may be entirely obscured by the horn of T1; the lateral ocellus is often close to the inner orbit of the compound eye; and the horn of T1 is missing in some members of the P. nephta species group.

Previous authors have mentioned that Paridris may be confused with Probaryconus (Galloway and Austin 1984) and Anteris Förster (Masner 1976). Masner (1976) indicated that Anteris and Neotropical Paridris are close to each other, and indeed they are highly similar in most of the external characters typically used for identification. Based on a yet unpublished phylogeny, we consider many of the similarities between these two genera to be convergent and not indicative of close relationship.

Separation of Paridris from Probaryconus is a more complicated matter because both are polytypic. Probaryconus has neither notauli (Fig. 9-10) nor an externally developed metascutellum (Figs 9-10), and always has spines, points, or dense tufts of setae on the propodeum (Figs 9-10). The epomial carina (Fig. 7) is present in Probaryconus (always absent in Paridris), with the exception of one widespread species group (Fig. 8) that also has setose eyes and a strongly reduced postmarginal vein. The 
transverse carina of T2 (Fig. 12) unambiguously identifies Paridris but is not present in all species (e.g. the P. nephta species group). In some Neotropical and Oceanic species of Paridris, the lateral propodeal carinae form two points lateral to the metasomal depression, similar to the propodeal points in Probaryconus Kieffer. The following key separates Probaryconus and Anteris from Paridris with the fewest characters possible.

\section{Key to separate Paridris, Probaryconus and Anteris}

1 Palpal formula 2-1 (Fig. 1); female T7+8, when extruded with ovipositor, connected to T6 by short, unsegmented conjunctiva (Fig. 3) Anteris

- $\quad$ Palpal formula 4-2 (Fig. 2); female T7+8, when extruded with ovipositor, connected to T6 by long, segmented conjunctiva (Fig. 4) .......................2

2 Metanotum visible medially and unaltered by horn of T1, or horn absent (Figs 10, 12) .............................................................................. 3

- $\quad$ Metanotum obscured medially by horn of T1 (Figs 9, 11) .......................4

3 Metascutellum visible externally, shape variable (Fig. 12) ................Paridris

- Metascutellum not visible externally (Fig. 10) .......................Probaryconus

4 Lateral ocellus remote from inner orbit, separated by distance of at least one ocellar diameter (Fig. 11) .........................................................Paridris

- $\quad$ Lateral ocellus contiguous with inner orbit or separated by distance less than one ocellar diameter (Fig. 10)

Probaryconus

\section{Diagnosis of nephta species group}

The $P$. nephta species group can be separated from the remainder of Paridris by the combination of the following characters: occipital carina reaching base of mandible; mesoscutal suprahumeral sulcus absent mesal to notaulus; scutoscutellar and posterior scutellar sulci comprised of deep cells; metascutellum bispinose, glabrous; mesepisternum below femoral groove with coarse rugose sculpture; paracoxal and metapleural sulci not fused in dorsal half of metapleuron (Fig. 32); posterior margin of metapleuron with triangular point above metapleural sulcus; propodeum coarsely punctate rugose; plica indistinguishable or poorly distinguished from background sculpture of propodeum; anterior T2 without transverse carina; T6 evenly rounded, without dense microsculpture; felt field on S2 punctate, present throughout length of sternite.

Sexual dimorphism combined with the small number of males prevented us from associating males with females for all but two species, P. mystax and P. nephta. Consequently, only females are treated in the key and descriptions. Males for $P$. mystax and $P$. nephta have been entered as determined material, but not as paratypes for $P$. mystax. Four other male morphotypes have been imaged and can be found online at specimage.osu.edu and www.morphbank.net ${ }^{8,9,10,11}$. 


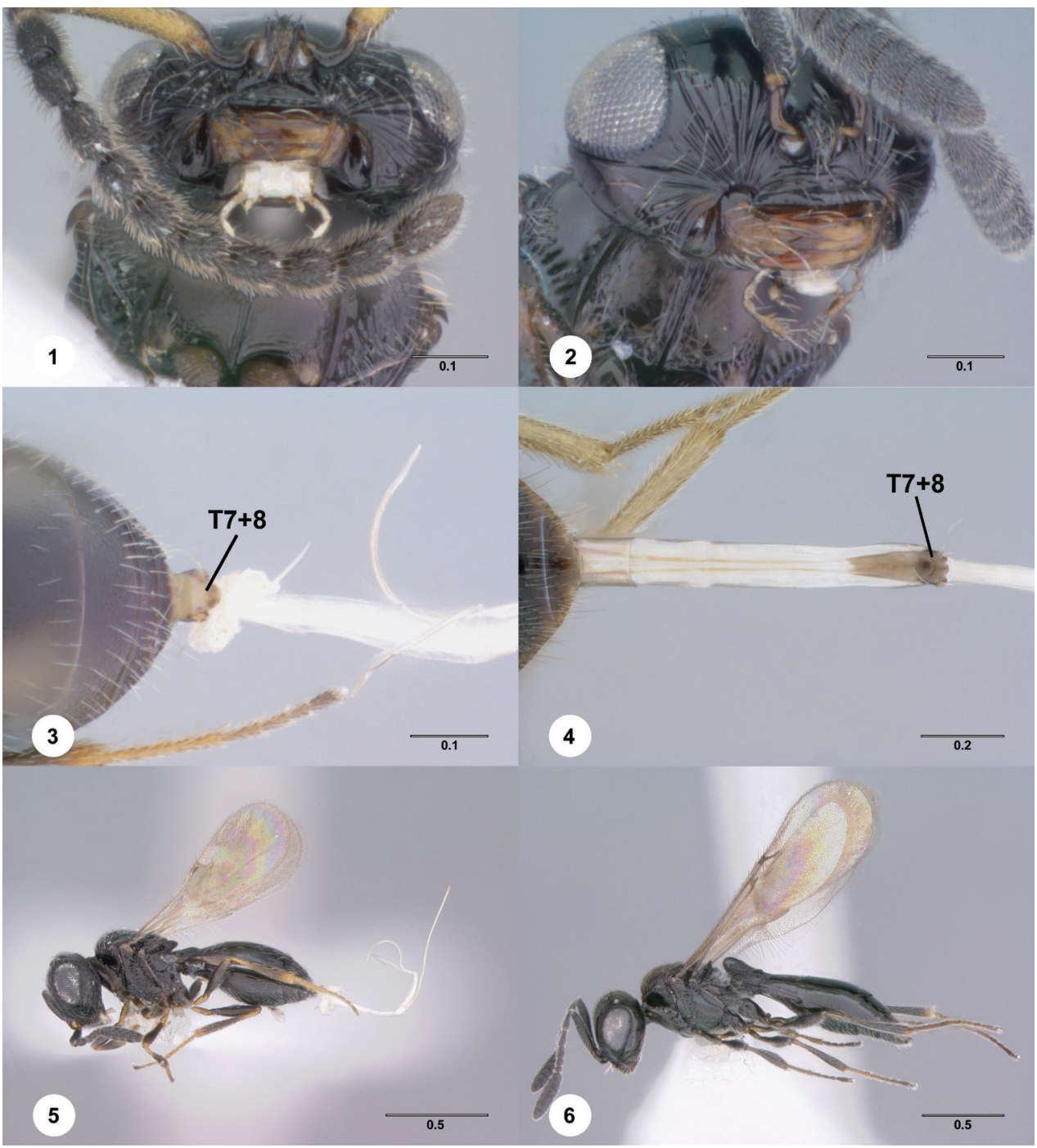

Figure I-6.62 I Anteris sp., head, mouthparts, ventral view, male (OSUC 241115) 2 Paridris sp., head, mouthparts, anteroventral view, female (OSUC 190976) 3 Anteris sp., T5-T7, ovipositor, female (OSUC 261917) 4 Paridris nilaka, T6-T7, ovipositor, female (OSUC 266165) 5 Anteris sp., lateral habitus, female (OSUC 261917) 6 Paridris sp., lateral habitus, female (OSUC 191490). Scale bar in millimeters.

Key to females of the Paridris nephta species group (a Lucid key is included as a Appendix II).

1 Brachypterous, forewing not reaching apex of metasoma in repose (Figs 31,

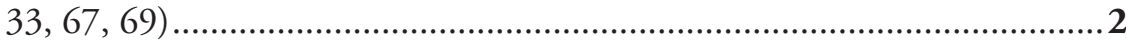

- $\quad$ Macropterous, forewing extending beyond apex of metasoma in repose...... 3 
A7 with basiconic sensillum (Fig. 14); sculpture of T3 reduced medially (Fig. 33); metapleural sulcus simple dorsally (Fig. 36)

Paridris ferus Talamas, sp. $\mathbf{n}$.

A7 without basiconic sensillum (Fig. 13); sculpture of T3 not reduced medially (Fig. 72); metapleural sulcus foveolate dorsally (Fig. 68)

Paridris reptilis Talamas, sp. $\mathbf{n}$.

Ventral clypeal margin edentate (Fig. 89); T3 covered in finely reticulate microsculpture (Fig. 90) Paridris teres Talamas, sp. $\mathbf{n}$. Ventral clypeal margin serrate (Figs 53, 101, 107); sculpture of T3 variable...4 Ventral metapleural area entirely setose (Fig. 50); frons densely setose ventrolaterally (Fig. 53); head and metasoma black (Fig. 49)

Paridris mystax Talamas, sp. n.

Ventral metapleural area with glabrous area (Fig. 62); frons moderately to sparsely setose ventrolaterally (Fig. 107); body color variable .5 Notaulus absent or indicated only at posterior margin of mesoscutum (Figs 22, 106).

Notaulus present through posterior half of mesoscutum, usually reaching mesoscutal suprahumeral sulcus as smooth furrow or row of punctures (Figs $58,76)$

T1-T5, S3 with microsculpture throughout (Figs 17, 102); T3 evenly reticulate in medial third (Fig. 102) Paridris verrucosus Talamas, sp. $\mathbf{n}$. Metasoma without microsculpture (Figs 18, 105); T3 longitudinally strigose (Figs 12, 105) .7 Frons immediately below median ocellus smooth (Fig. 23); axillular carina rounded dorsally (Fig. 16); S3 with longitudinal striae (Fig. 18)

Paridris atrox Talamas, sp. $\mathbf{n}$. Frons immediately below median ocellus rugose, with setigerous foveae (Fig. 107); axillular carina pointed dorsally (Fig. 15); S3 without longitudinal striae Paridris yak Talamas, sp. n. A7 with basiconic sensillum (Fig. 14) ....................................................... A7 without basiconic sensillum (Fig. 13) ..............................................10

R1 (postmarginal vein) distinctly shorter than r-rs (stigmal vein) (Fig. 109); T3 smooth with weakly impressed longitudinal striae laterally (Fig. 30), microsculpture absent; punctation of head fine (Fig. 29).

Paridris bunun Talamas, sp. $\mathrm{n}$.

R1 (postmarginal vein) about as long as r-rs (stigmal vein) (Fig. 111); T3 with prominent longitudinal strigae laterally, often strigose throughout, microsculpture usually present (Fig. 48); punctation of head variable, often coarse (Fig. 47). Paridris minator Talamas, sp. $\mathbf{n}$. Mesoscutellum punctate, interspaces between punctures smooth and usually broad (Figs. 58, 82) 11

- $\quad$ Mesoscutellum rugulose to areolate (Figs 40, 63, 76, 94) 12 


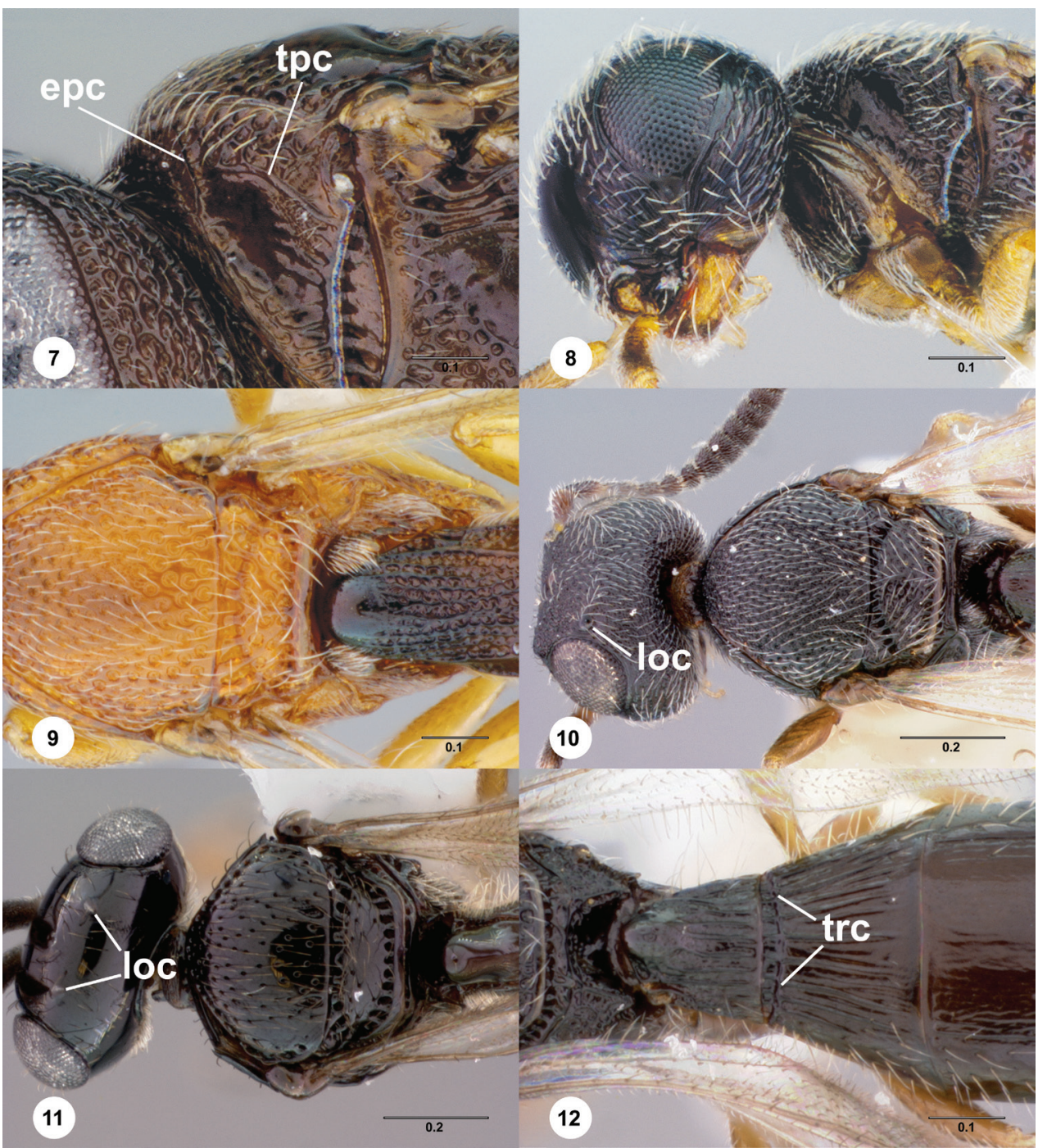

Figures 7-12.63 7 Probaryconus sp., pronotum, lateral view, female (OSUC 146809) 8 Probaryconus sp., head and pronotum, female (OSUC 58741) 9 Probaryconus sp., mesosoma and T1, dorsal view, female (OSUC 404933) 10 Probaryconus rufipes (Kieffer), head and mesosoma, dorsal view, female (OSUC 396820) II Paridris sp., head, mesosoma, T1, dorsal view, female (OSUC 262120) I 2 Paridris sp., metascutellum, propodeum, T1-T2, dorsal view, female (OSUC 265183). Scale bar in millimeters.

11 Frons evenly striate throughout, striae directly above interantennal process sometimes effaced (Fig. 59); interstitial punctation on frons very fine (Fig. 59) Paridris nephta (Kozlov) 
- $\quad$ Frons directly below median ocellus coarsely strigose to rugose; frons always with smooth area above interantennal process; interstitial punctation on frons coarse (Fig. 83)

Paridris solaris Talamas, sp. $\mathbf{n}$.

12 Frons evenly striate throughout, with microsculpture present interstitially (Fig. 41)..... Paridris kagemono Talamas, sp. n.

- Striae of frons, if present, not uniform throughout, microsculpture absent (Figs 65, 77, 95) 13

13 Pronotum with uniform, fine, white setae along transverse pronotal carina (Fig. 66); body dark brown to black (Fig. 61)

Paridris nilaka Talamas, sp. $\mathbf{n}$.

- $\quad$ Pronotum with dark, bristlelike setae along transverse pronotal carina (Figs $77,94)$; body color variable ....................................................... 14

14 Pronotum below transverse pronotal carina mostly smooth, with sparse rugulae (Fig. 77) Paridris rugulosus Talamas, sp. n.

- $\quad$ Pronotum below transverse pronotal carina densely punctate (as in Fig. 66)...

Paridris toketoki Talamas, sp. n.

Paridris atrox Talamas, sp. $n$.

urn:Isid:zoobank.org:pub:BCD3BD6E-5E29-447F-AEB6-176C19EEF3E8

urn:Isid:biosci.ohio-state.edu:osuc_concepts:275737

http://species-id.net/wiki/Paridris_atrox

Figures 16, 19-24; Morphbank ${ }^{12}$

Description. Female body length: $2.73 \mathrm{~mm}(\mathrm{n}=1)$. Color of head: reddish brown. Ventral clypeal margin: serrate. Sculpture of frons medially: smooth. Sculpture of frons immediately ventral of median ocellus: dorsoventrally strigose laterally. Microsculpture of frons: absent. Sculpture of posterior vertex: irregularly rugulose. Sculpture of gena: irregularly rugulose. Basiconic sensillum on A7: absent.

Wings: macropterous, apex of forewing extending beyond posterior margin of T3. Length of R1: equal to r-rs. Notaulus: absent. Color of mesosoma: variably orange to brown. Sculpture of mesoscutum medially: areolate rugulose. Sculpture of mesoscutellum: areolate rugulose. Dark bristlelike setae along transverse pronotal carina: present. Sculpture ventral of transverse pronotal carina: rugulose posteriorly. Sculpture of femoral groove: striate below mesopleural pit. Sculpture of ventral half of posterior mesepimeral area: rugulose. Fine setigerous punctures on dorsal half of posterior mesepimeral area: absent. Mesopleural carina: present. Setation of ventral metapleural area: absent in area immediately below metapleural sulcus. Setation of metapleural triangle: moderately dense. Color of legs: yellow throughout. 


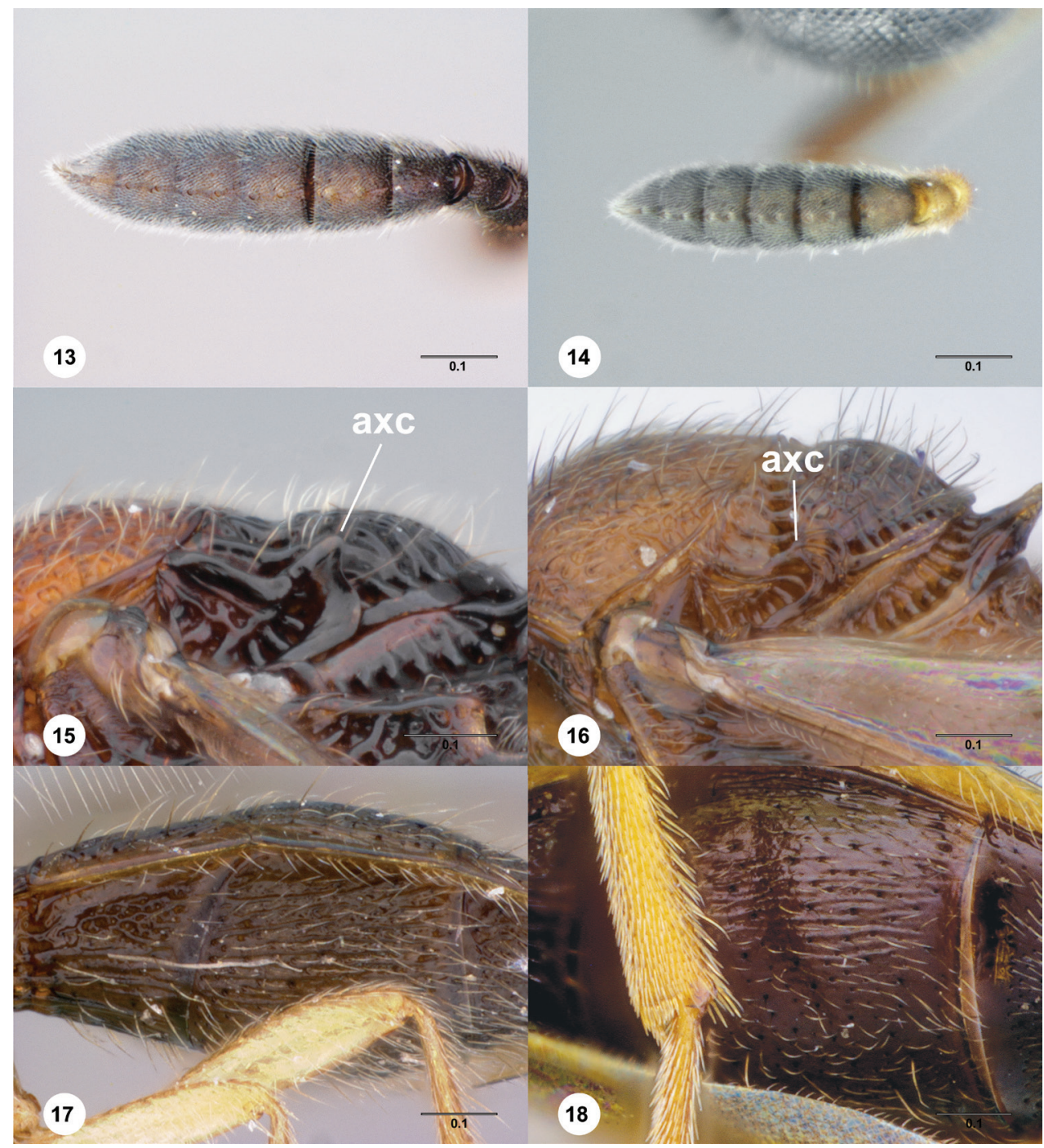

Figures 13-18.64 I3 Paridris nilaka, sp. n., antennal clava, ventral view, female (OSUC 334247) 14 Paridris minator, sp. n., antennal clava, ventral view, female holotype (OSUC 237531) I 5 Paridris yak,sp. n, scuto-axillar complex, lateral view, female holotype (OSUC 237530) 16 Paridris atrox, sp. n., scuto-axillar complex, lateral view, female holotype (OSUC 241473) I7 Paridris verrucosus, sp. n., S2-S3, ventrolateral view, female holotype (OSUC 334249) 18 Paridris atrox, sp. n., S3, ventrolateral view, female holotype (OSUC 241473). Scale bars in millimeters.

Color of metasoma: reddish brown. Horn of T1: bulge smooth, at least anteriorly. Microsculpture of T2: absent. Microsculpture on T3: absent. Macrosculpture of T3 medially: weakly longitudinally strigose. Macrosculpture of T3 laterally: longitudinally strigose. Microsculpture of T4: absent. Macrosculpture of T4 laterally: weakly rugulose. Punctation of T4: moderately dense throughout. Macrosculpture of T5: absent. 


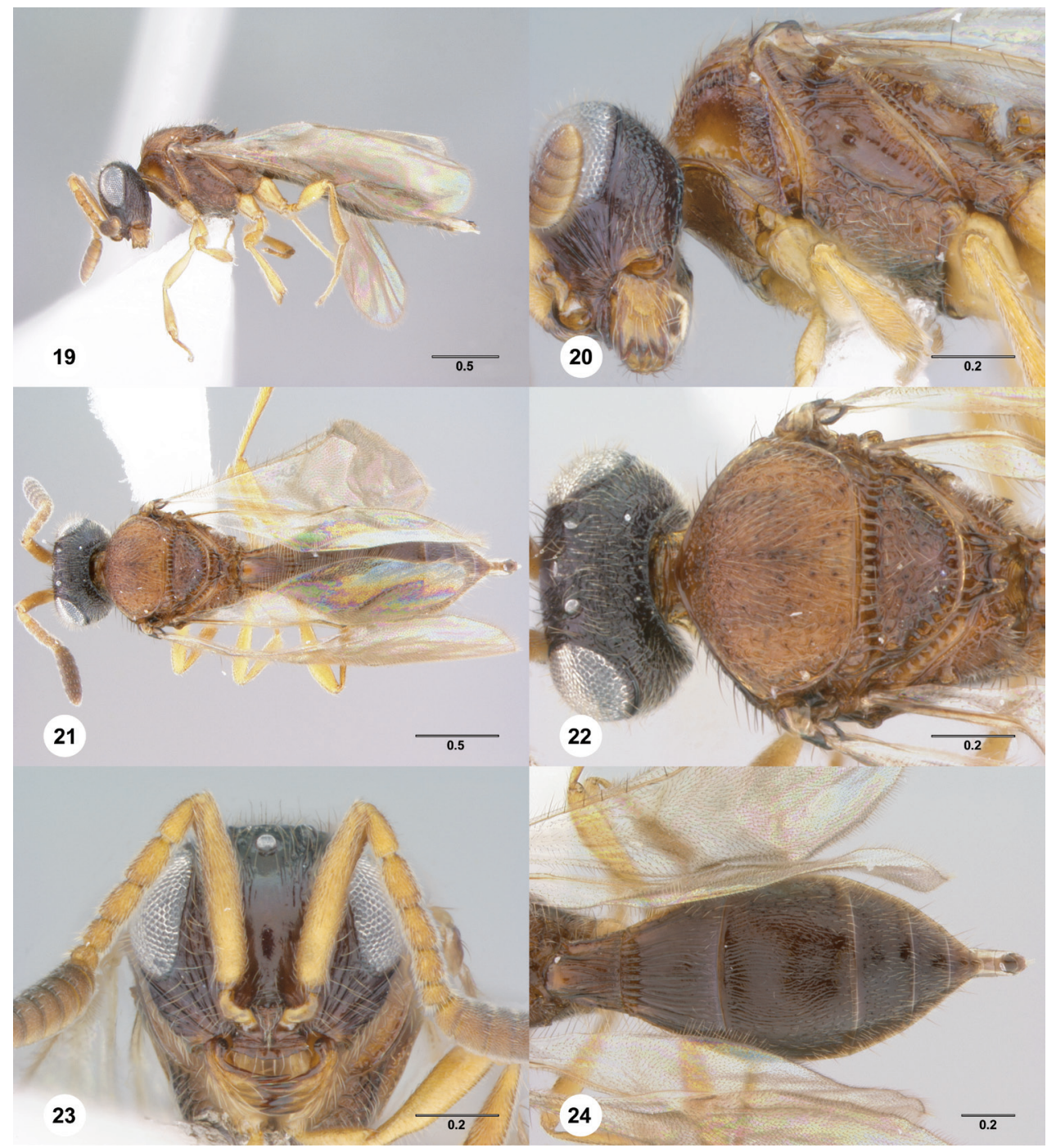

Figures 19-24.65 Paridris atrox sp. n., female holotype (OSUC 241473) 19 Lateral habitus 20 Head and mesosoma, lateral view $\mathbf{2} \mathbf{I}$ Dorsal habitus $\mathbf{2 2}$ Head and mesosoma, dorsal view $\mathbf{2 3}$ Head, anterior view 24 Metasoma, dorsal view. Scale bars in millimeters.

Punctation of T5: moderately dense throughout. Microsculpture of S3: absent. Macrosculpture of S3 laterally: weakly longitudinally strigose.

Diagnosis. Paridris atrox may be separated from the other members of the P. nephta species group by the absence of notauli and the presence of striation on S3.

Etymology. Paridris atrox is named for the severe appearance of its head, its mandibles in particular. The specific epithet is adjectival, and means "fearsome" in Latin. 
Material Examined. Holotype, female: CHINA: Yunnan Prov., Baoshan City, 28 $\mathrm{km}$ (air)SE Tengyue (Teng Chong), pass over Gaoligong Mts., clearing / natural forest, Luoshuidong, $24^{\circ} 57^{\prime} \mathrm{N} 98^{\circ} 45^{\prime} \mathrm{E}, 2300 \mathrm{~m}, 26 . \mathrm{X}-31 . X .1998$, flight intercept trap, C. Griswold, D. Kavanaugh \& C. L. Long, OSUC 241473 (deposited in IZCAS).

\section{Paridris bunun Talamas, sp. $\mathrm{n}$.}

urn:Isid:zoobank.org:act:A3CA8ADB-0B8F-47C1-A757-9CEAE44779A2

urn:lsid:biosci.ohio-state.edu:osuc_concepts:273886

http://species-id.net/wiki/Paridris_bunun

Figures 25-30; Morphbank ${ }^{14}$

Description. Female body length: $3.41 \mathrm{~mm}(\mathrm{n}=1)$. Color of head: dark red, becoming darker dorsally. Ventral clypeal margin: serrate. Sculpture of frons medially: smooth. Sculpture of frons immediately ventral of median ocellus: dorsoventrally strigose laterally. Microsculpture of frons: absent. Sculpture of posterior vertex: finely punctate. Sculpture of gena: densely and finely punctate. Basiconic sensillum on A7: present.

Wings: macropterous, apex of forewing extending beyond posterior margin of T3. Length of R1: less than r-rs. Notaulus: present in posterior half of mesoscutum. Color of mesosoma: variably red to black. Sculpture of mesoscutum medially: densely punctate throughout. Sculpture of mesoscutellum: densely punctate. Dark bristlelike setae along transverse pronotal carina: absent. Sculpture ventral of transverse pronotal carina: finely punctate. Sculpture of femoral groove: smooth. Sculpture of ventral half of posterior mesepimeral area: smooth. Fine setigerous punctures on dorsal half of posterior mesepimeral area: present. Mesopleural carina: present along anterior half of femoral groove. Setation of ventral metapleural area: absent in area immediately below metapleural sulcus. Setation of metapleural triangle: moderately dense. Color of legs: yellow throughout.

Color of metasoma: reddish brown. Horn of T1: bulge smooth, at least anteriorly. Microsculpture of T2: absent. Microsculpture on T3: absent. Macrosculpture of T3 medially: absent. Macrosculpture of T3 laterally: weakly longitudinally strigose. Microsculpture of T4: absent. Macrosculpture of T4 laterally: weakly longitudinally strigose. Punctation of T4: sparse in medial third, moderately dense laterally. Macrosculpture of T5: absent. Punctation of T5: absent in medial third, moderately dense laterally. Microsculpture of S3: absent. Macrosculpture of S3 laterally: absent.

Diagnosis. Paridris bunun is most similar to P. minator, though the two have widely disjunct distributions, Taiwan and Southeast Asia, respectively. The two may be separated by the medially smooth T3 and short R1 (postmarginal vein) of P. bunun and the longer setation of the body in P. minator. P. bunun is a much larger species than $P$. minator, but it is known from a single specimen and thus we are not able to assess its size variation. Some species of the $P$. nephta group are known to exhibit significant size variation (e.g. P. nilaka) and thus size should be used cautiously. 


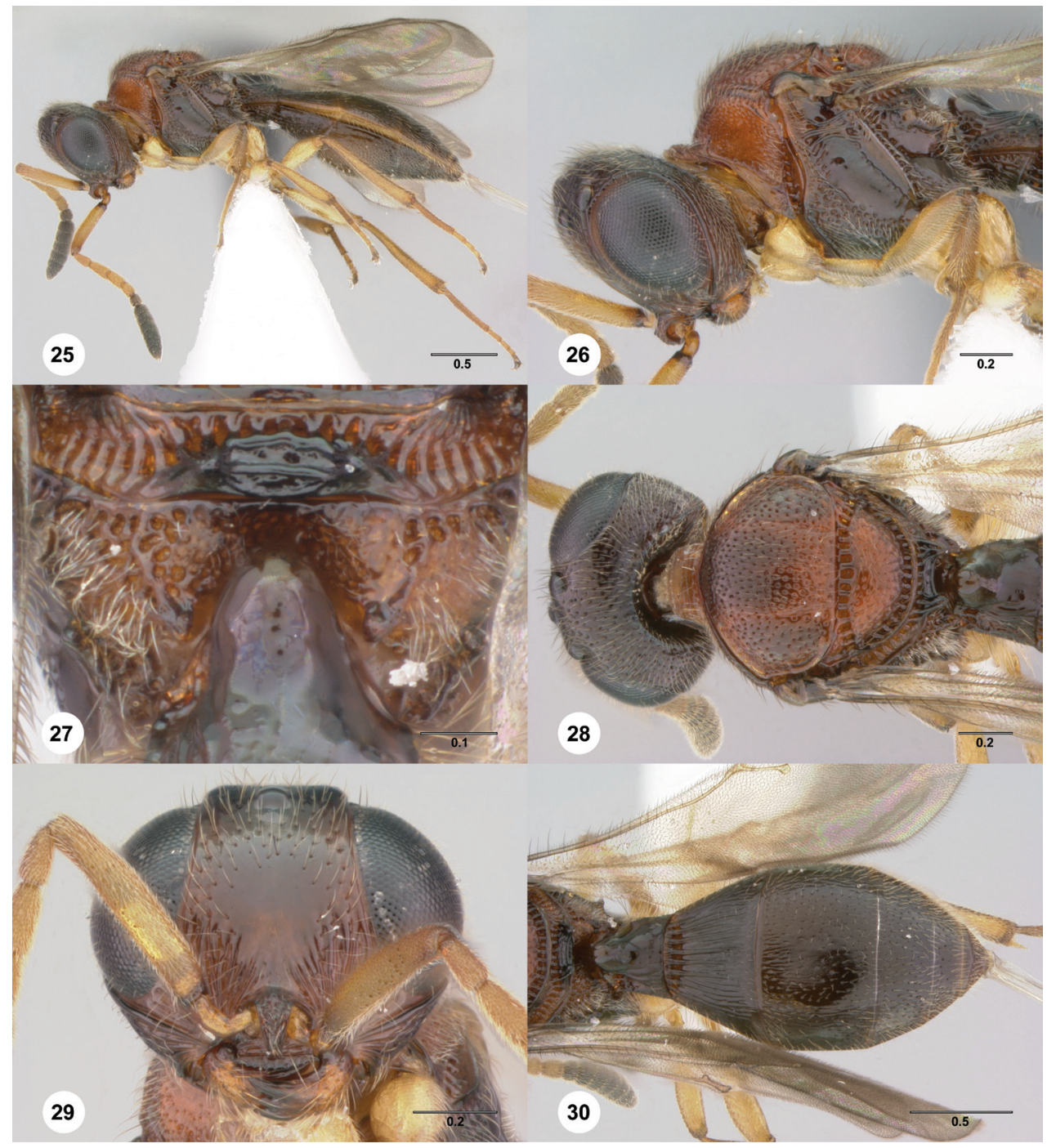

Figures 25-30. ${ }^{66}$ Paridris bunun sp. n., female holotype (OSUC 262237) 25 Lateral habitus 26 Head and mesosoma, lateral view 27 Propodeum, posterodorsal view $28 \mathrm{Head}$ and mesosoma, dorsal view 29 Head, anterior view $\mathbf{3 0}$ Metasoma, dorsal view. Scale bars in millimeters.

Etymology. The species is named for the Bunun tribe of Taiwan that historically occupied the region where it was collected. The name is treated as a noun in apposition.

Link to Distribution Map. ${ }^{15}$

Material Examined. Holotype, female: TAIWAN: Taiwan Prov., Pingtung Co., T'eng-chih (Tengchi) Medium-Altitude Experiment Station, $23^{\circ} 05.75^{\prime} \mathrm{N} 120^{\circ} 47.37^{\prime} \mathrm{E}$, 1660m, 3.VI-5.VI.2008, yellow pan trap, L. Masner, OSUC 262237 (deposited in CNCI). 


\section{Paridris ferus Talamas, sp. n.}

urn:lsid:zoobank.org:act:6B7296C1-4E71-4A35-B937-ABB1949B7DBE

urn:lsid:biosci.ohio-state.edu:osuc_concepts:241281

http://species-id.net/wiki/Paridris_ferus

Figures 31-36; Morphbank ${ }^{16}$

Description. Female body length: $2.89 \mathrm{~mm}(\mathrm{n}=1)$. Color of head: black throughout. Ventral clypeal margin: serrate. Sculpture of frons medially: smooth. Sculpture of frons immediately ventral of median ocellus: dorsoventrally striate throughout. Microsculpture of frons: absent. Sculpture of posterior vertex: punctate rugulose. Sculpture of gena: dorsoventrally strigose. Basiconic sensillum on A7: present.

Wings: brachypterous, apex of forewing ending before T4. Notaulus: percurrent. Color of mesosoma: variably orange to brown. Sculpture of mesoscutum medially: densely punctate, with longitudinal rugae in posterior half. Sculpture of mesoscutellum: smooth along midline, otherwise punctate rugulose. Dark bristlelike setae along transverse pronotal carina: absent. Sculpture ventral of transverse pronotal carina: finely punctate. Sculpture of femoral groove: striate in ventral end. Sculpture of ventral half of posterior mesepimeral area: smooth. Fine setigerous punctures on dorsal half of posterior mesepimeral area: present. Mesopleural carina: present along anterior half of femoral groove. Setation of ventral metapleural area: absent in area immediately below metapleural sulcus. Setation of metapleural triangle: dense. Color of legs: pale brown throughout.

Color of metasoma: orange to brown. Horn of T1: bulge smooth, at least anteriorly. Microsculpture of T2: absent. Microsculpture on T3: absent. Macrosculpture of T3 medially: absent. Macrosculpture of T3 laterally: longitudinally strigose. Microsculpture of T4: absent. Macrosculpture of T4 laterally: absent. Punctation of T4: moderately dense throughout. Macrosculpture of T5: absent. Punctation of T5: moderately dense throughout. Microsculpture of S3: absent. Macrosculpture of S3 laterally: longitudinally strigose.

Diagnosis. Paridris ferus and P. reptilis are the only brachypterous species known in the P. nephta group. Aside from this character, these two species are not particularly similar and may be separated by the presence of a basiconic sensillum on A7, the smooth form of the metapleural sulcus and longitudinal striation of S3 in P. ferus.

Etymology. The adjectival epithet "ferus" means "wild" or "untamed" in Latin and refers to the "savage" appearance of this species.

\section{Link to Distribution Map. ${ }^{17}$}

Material Examined. Holotype, female: THAILAND: Chiang Mai Prov., summit forest, T178, Doi Inthanon National Park, $18^{\circ} 35.361^{\prime} \mathrm{N} 98^{\circ} 29.157^{\prime} \mathrm{E}, 2500 \mathrm{~m}$, 9.VIII-16.VIII.2006, malaise trap, Y. Areeluck, OSUC 192426 (deposited in QSBG). 


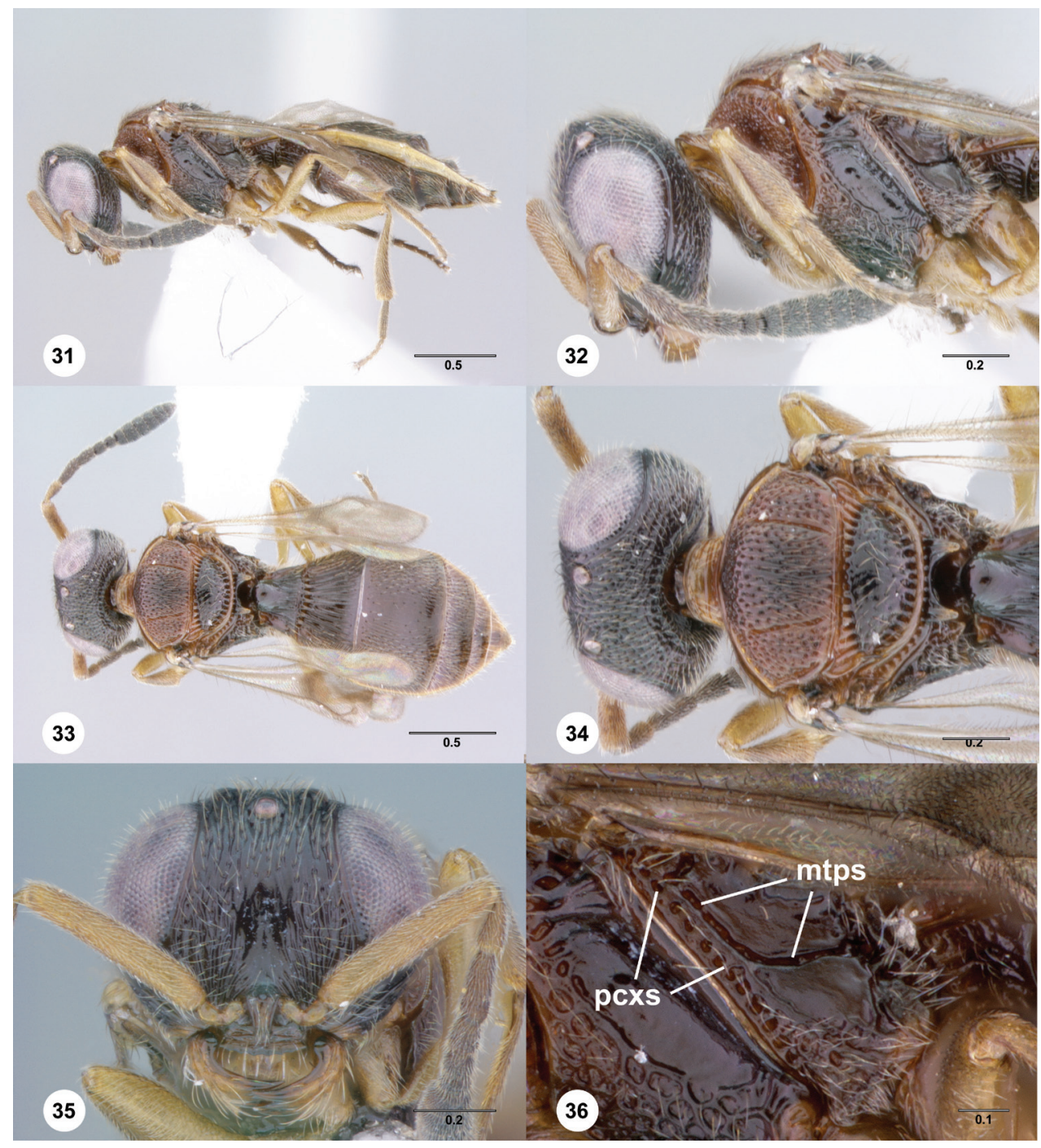

Figures 3 I-36. ${ }^{67}$ Paridris ferus sp. n., female holotype (OSUC 192426) $\mathbf{3}$ I Lateral habitus 32 Head and mesosoma, lateral view $\mathbf{3 3}$ Dorsal habitus $\mathbf{3 4}$ Head and mesosoma, dorsal view $\mathbf{3 5}$ Head, anterior view 36 Metapleuron, lateral view. Scale bars in millimeters. 


\section{Paridris kagemono Talamas, sp. n.}

urn:Isid:zoobank.org:act:59410F97-5DD7-4E7E-A7C3-2F25DD7665AE

urn:Isid:biosci.ohio-state.edu:osuc_concepts:273916

http://species-id.net/wiki/Paridris_kagemono

Figures 37-42; Morphbank ${ }^{18}$

Description. Female body length: $2.65 \mathrm{~mm}(\mathrm{n}=1)$. Color of head: dark orange, becoming brown at vertex. Ventral clypeal margin: serrate. Sculpture of frons medially: dorsoventrally striate. Sculpture of frons immediately ventral of median ocellus: dorsoventrally striate throughout. Microsculpture of frons: present. Sculpture of posterior vertex: punctate rugulose. Sculpture of gena: irregularly rugulose. Basiconic sensillum on A7: absent.

Wings: macropterous, apex of forewing extending beyond posterior margin of T3. Length of R1: less than r-rs. Notaulus: percurrent. Color of mesosoma: orange throughout. Sculpture of mesoscutum medially: densely punctate throughout. Sculpture of mesoscutellum: punctate rugulose throughout. Dark bristlelike setae along transverse pronotal carina: absent. Sculpture ventral of transverse pronotal carina: punctate rugulose. Sculpture of femoral groove: striate below mesopleural pit. Sculpture of ventral half of posterior mesepimeral area: smooth. Fine setigerous punctures on dorsal half of posterior mesepimeral area: present. Mesopleural carina: absent. Setation of ventral metapleural area: absent in area immediately below metapleural sulcus. Setation of metapleural triangle: moderately dense. Color of legs: yellow throughout.

Color of metasoma: orange throughout. Horn of T1: absent. Microsculpture of T2: present. Microsculpture on T3: present. Macrosculpture of T3 medially: reticulate rugose. Macrosculpture of T3 laterally: reticulate rugose. Microsculpture of T4: absent. Macrosculpture of T4 laterally: weakly rugulose. Punctation of T4: moderately dense throughout. Macrosculpture of T5: absent. Punctation of T5: moderately dense throughout. Microsculpture of S3: absent. Macrosculpture of S3 laterally: absent.

Diagnosis. Paridris kagemono is most similar to P. nephta. It may be separated from it, and all other members of the P. nephta species group, by the presence of microsculpture between the striae of the frons.

Etymology. The epithet "kagemono" means "supernatural creature of the night" in Japanese. It is used as a noun in apposition.

\section{Link to Distribution Map. ${ }^{19}$}

Material Examined. Holotype, female: JAPAN: Fukuoka Pref., Kyushu Isl., primary evergreen forest, Mount Tachibana, 1.VII-6.VII.1979, yellow pan trap, K. Yamagishi, OSUC 262193 (deposited in CNCI). 


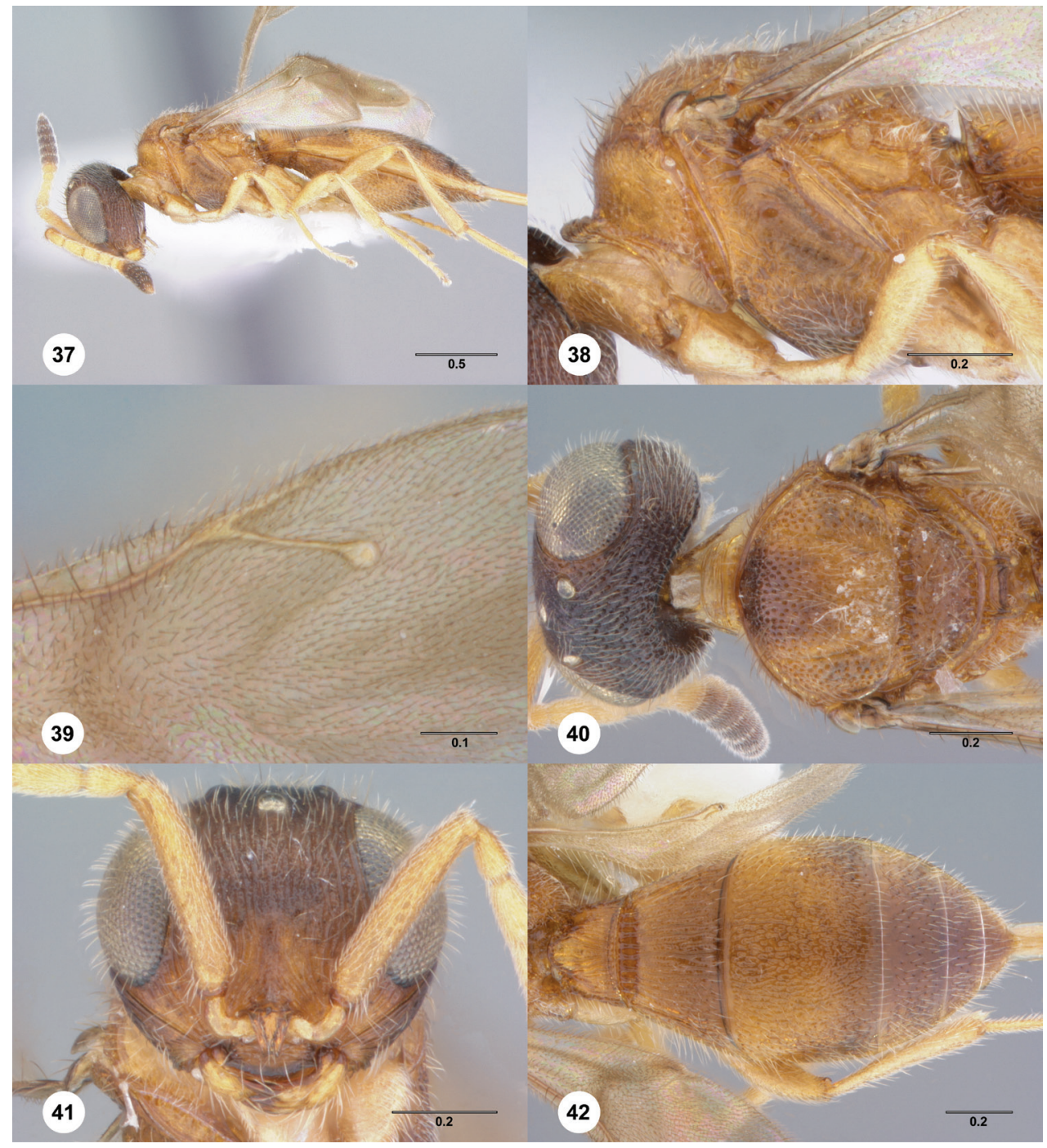

Figures 37-42. ${ }^{68}$ Paridris kagemono sp. n., female holotype (OSUC 262193) 37 Lateral habitus 38 Mesosoma, lateral view $\mathbf{3 9}$ Forewing, dorsal view $\mathbf{4 0} \mathrm{Head}$ and mesosoma, dorsal view $\mathbf{4}$ I Head, anterior view 42 Metasoma, dorsal view. Scale bars in millimeters. 


\section{Paridris minator Talamas, sp. $\mathbf{n}$.}

urn:lsid:zoobank.org:act:6A07840D-7470-4B42-89E2-7012B99C6C8F

urn:lsid:biosci.ohio-state.edu:osuc_concepts:241284

http://species-id.net/wiki/Paridris_minator

Figures 14, 43-48; Morphbank ${ }^{20}$

Description. Female body length: $2.27-2.53 \mathrm{~mm}(\mathrm{n}=9)$. Color of head: uncertain, reddish brown. Ventral clypeal margin: serrate. Sculpture of frons medially: smooth. Sculpture of frons immediately ventral of median ocellus: dorsoventrally strigose throughout; rugose. Microsculpture of frons: absent. Sculpture of posterior vertex: finely punctate; punctate rugulose. Sculpture of gena: punctate rugulose; densely and finely punctate. Basiconic sensillum on A7: present.

Wings: macropterous, apex of forewing extending beyond posterior margin of T3. Length of R1: equal to r-rs; longer than r-rs. Notaulus: percurrent. Color of mesosoma: variably red to black. Sculpture of mesoscutum medially: densely punctate throughout. Sculpture of mesoscutellum: densely punctate. Dark bristlelike setae along transverse pronotal carina: absent. Sculpture ventral of transverse pronotal carina: finely punctate. Sculpture of femoral groove: smooth. Sculpture of ventral half of posterior mesepimeral area: smooth. Fine setigerous punctures on dorsal half of posterior mesepimeral area: present. Mesopleural carina: present. Setation of ventral metapleural area: absent in area immediately below metapleural sulcus. Setation of metapleural triangle: moderately dense. Color of legs: pale brown throughout; yellow throughout.

Color of metasoma: dark brown to black throughout; reddish brown. Horn of T1: bulge smooth, at least anteriorly. Microsculpture of T2: absent. Microsculpture on T3: present. Macrosculpture of T3 medially: reticulate; longitudinally strigose; weakly longitudinally strigose. Macrosculpture of T3 laterally: longitudinally strigose. Microsculpture of T4: absent. Macrosculpture of T4 laterally: weakly rugulose; absent. Punctation of T4: moderately dense throughout. Macrosculpture of T5: absent. Punctation of T5: moderately dense throughout. Microsculpture of S3: absent. Macrosculpture of S3 laterally: absent.

Diagnosis. Paridris minator is similar to $P$. solaris in size, habitus and distribution and to $P$. bunun in its diagnostic characters. It is best separated from $P$. solaris by the presence of a basiconic sensillum on A7 and from P. bunun by the coarse punctation of the head and prominent striae of lateral T3.

Etymology. The Latin epithet "minator" means "threatener" and is given to this species for its fierce appearance.

\section{Link to Distribution Map. ${ }^{21}$}

Material Examined. Holotype, female: THAILAND: Chiang Mai Prov., checkpoint 2, T73, Doi Inthanon National Park, 18³1.559'N 98²9.941'E, 1700m, 


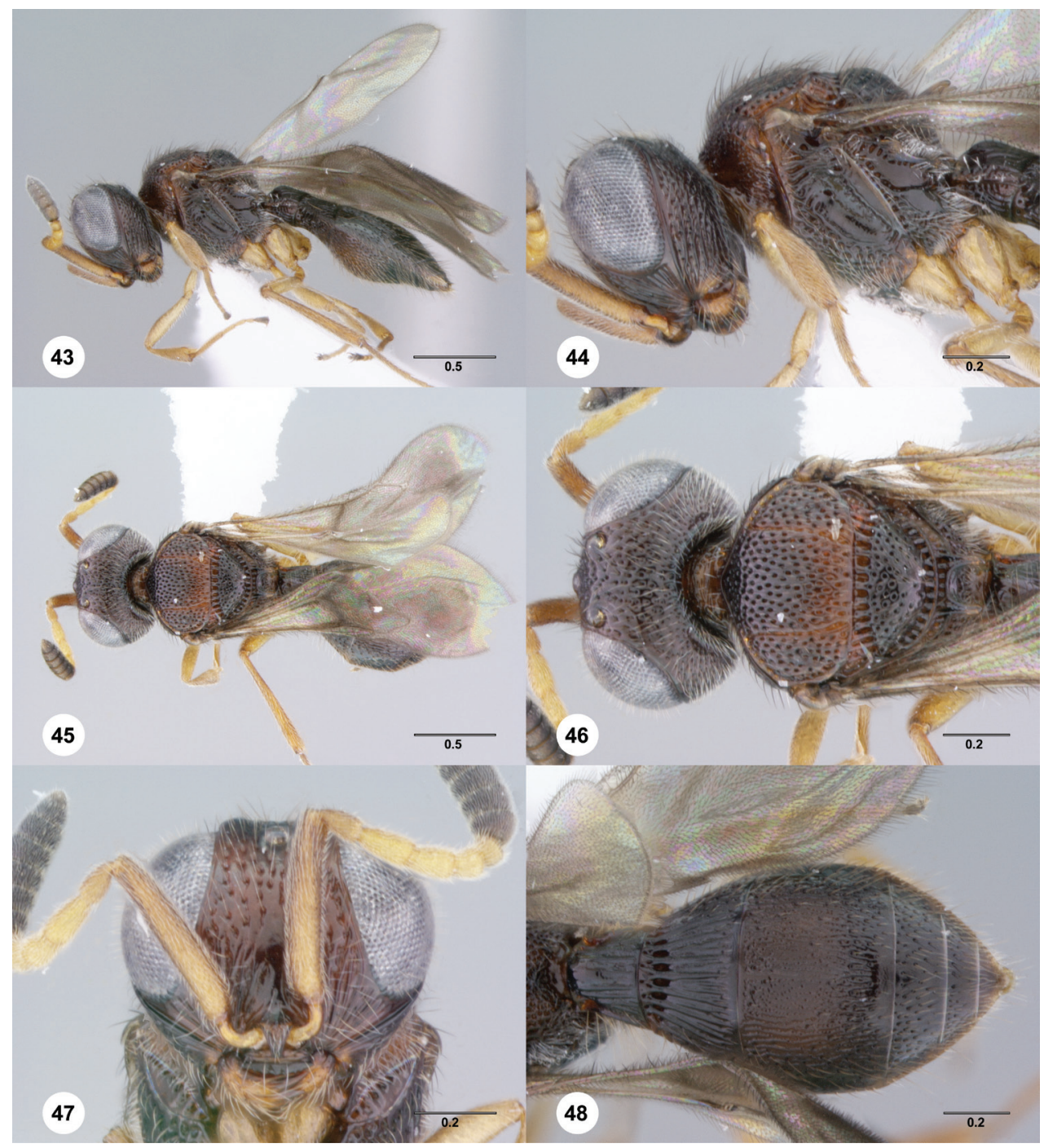

Figures 43-48. ${ }^{69}$ Paridris minator sp. n., female holotype (OSUC 237531) 43 Lateral habitus 44 Head and mesosoma, lateral view $\mathbf{4 5}$ Dorsal habitus $\mathbf{4 6} \mathrm{Head}$ and mesosoma, dorsal view $\mathbf{4 7} \mathrm{Head}$, anterior view 48 Metasoma, dorsal view. Scale bars in millimeters.

15.VII-22.VII.2006, malaise trap, Y. Areeluck, OSUC 237531 (deposited in QSBG). Paratypes: (8 females) LAOS: 1 female, OSUC 334241 (CNCI). THAILAND: 7 females, OSUC 262239, 334245, 396845 (CNCI); OSUC 334205 (OSUC); OSUC 334005, 334215, 334246 (QSBG). 


\section{Paridris mystax Talamas, sp. $\mathbf{n}$.}

urn:lsid:zoobank.org:act:67E77FD7-4ECC-494F-B7B0-497E4B82AB59

urn:Isid:biosci.ohio-state.edu:osuc_concepts:241282

http://species-id.net/wiki/Paridris_mystax

Figures 49-54, 111; Morphbank ${ }^{22}$

Description. Female body length: 2.53-3.26 mm $(\mathrm{n}=20)$. Color of head: black throughout. Ventral clypeal margin: serrate. Sculpture of frons medially: smooth. Sculpture of frons immediately ventral of median ocellus: dorsoventrally strigose throughout. Microsculpture of frons: absent. Sculpture of posterior vertex: punctate rugulose. Sculpture of gena: irregularly rugulose. Basiconic sensillum on A7: absent.

Wings: macropterous, apex of forewing extending beyond posterior margin of T3. Length of R1: equal to r-rs; less than r-rs. Notaulus: percurrent. Color of mesosoma: orange to dark red anteriorly, brown posteriorly, mesoscutellum black. Sculpture of mesoscutum medially: densely punctate throughout. Sculpture of mesoscutellum: punctate rugulose throughout; smooth along midline, otherwise punctate rugulose. Dark bristlelike setae along transverse pronotal carina: absent. Sculpture ventral of transverse pronotal carina: finely punctate. Sculpture of femoral groove: smooth; striate in ventral end. Sculpture of ventral half of posterior mesepimeral area: smooth. Fine setigerous punctures on dorsal half of posterior mesepimeral area: present. Mesopleural carina: present along anterior half of femoral groove. Setation of ventral metapleural area: present throughout. Setation of metapleural triangle: dense. Color of legs: yellow throughout.

Color of metasoma: orange to black. Horn of T1: bulge smooth, at least anteriorly. Microsculpture of T2: absent. Microsculpture on T3: present. Macrosculpture of T3 medially: reticulate; absent. Macrosculpture of T3 laterally: reticulate rugose. Microsculpture of T4: absent. Macrosculpture of T4 laterally: rugulose. Punctation of T4: dense throughout; moderately dense throughout. Macrosculpture of T5: weakly rugulose laterally; absent. Punctation of T5: dense throughout; moderately dense throughout. Microsculpture of S3: absent. Macrosculpture of S3 laterally: absent.

Diagnosis. Paridris mystax is one of the most distinctive species and can be easily identified by the dense setation throughout the ventral metapleural area and on the ventrolateral frons.

Etymology. The epithet "mystax", meaning "hair on the upper lip" in Greek, is given to this species for the conspicuous setation of the ventral frons.

\section{Link to Distribution Map. ${ }^{23}$}

Material Examined. Holotype, female: THAILAND: Loei Prov., Pong Neep Forest Unit, dry evergreen forest, T783, Phu Kradung National Park, $16^{\circ} 56.589^{\prime} \mathrm{N}$ $101^{\circ} 42.074$ 'E, 273m, 14.X-21.X.2006, malaise trap, S. Glong-lasae, OSUC 237667 (deposited in QSBG). Paratypes: (19 females) LAOS: 1 female, OSUC 265072 (CNCI). THAILAND: 18 females, OSUC 396840-396841, 396846 (CNCI); OSUC 


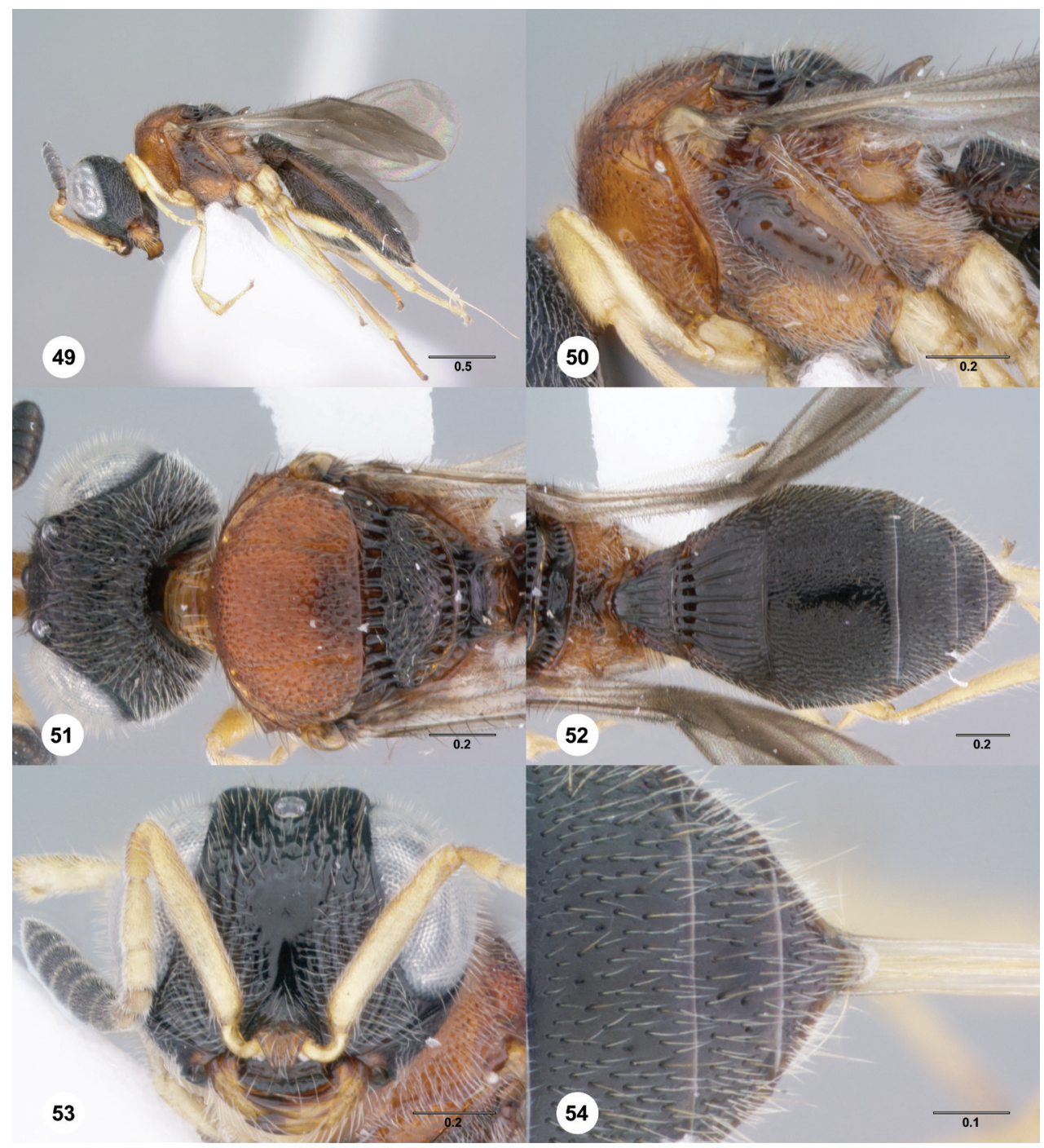

Figures 49-54. ${ }^{70}$ Paridris mystax sp. n. 49 Lateral habitus, female holotype (OSUC 237667) 50 Mesosoma, lateral view, female holotype (OSUC 237667) 5 I Head and mesosoma, dorsal view, female holotype (OSUC 237667) 52 Metasoma, dorsal view, female (OSUC 262229) 53 Head, anterior view, female (OSUC 237533) 54 T4-T6, dorsal view, female holotype (OSUC 237667). Scale bars in millimeters.

254570, 254594-254595, 334210, 381817, 396837 (OSUC); OSUC 237533, 254569, 265198-265199, 334209, 334224-334226, 334228 (QSBG). Other material: THAILAND: 18 males, OSUC 181202, 181292, 237529, 396844, 396847 (CNCI); OSUC 254552, 265200, 334208, 334211, 334216 (OSUC); OSUC 237666, 261871, 265201, 266164, 334202-334203, 334212, 334227 (QSBG). 


\section{Paridris nephta (Kozlov)}

urn:lsid:zoobank.org:act:C8471114-0E15-44FB-BFA4-2FE3A0E7EAE8

urn:lsid:biosci.ohio-state.edu:osuc_concepts:243854

http://species-id.net/wiki/Paridris_nephta

Figures 55-60; Morphbank ${ }^{24}$

Tuora nephta Kozlov, 1976: 98 (original description); Kozlov \& Kononova, 1990: 263 (description of male and female); Kononova, 1995: 86 (keyed).

Paridris nephta (Kozlov): Kononova \& Kozlov, 2008: 279, 281 (description, keyed, generic transfer).

Description. Female body length: $2.53-3.10 \mathrm{~mm}(\mathrm{n}=20)$. Color of head: dark brown to black. Ventral clypeal margin: serrate. Sculpture of frons medially: dorsoventrally striate. Sculpture of frons immediately ventral of median ocellus: dorsoventrally striate throughout. Microsculpture of frons: absent. Sculpture of posterior vertex: densely punctate. Sculpture of gena: finely punctate strigose; irregularly rugulose. Basiconic sensillum on A7: absent.

Wings: macropterous, apex of forewing extending beyond posterior margin of T3. Length of R1: equal to r-rs; less than r-rs. Notaulus: percurrent. Color of mesosoma: variably orange to brown. Sculpture of mesoscutum medially: densely punctate throughout. Sculpture of mesoscutellum: densely punctate. Dark bristlelike setae along transverse pronotal carina: absent. Sculpture ventral of transverse pronotal carina: finely punctate. Sculpture of femoral groove: striate below mesopleural pit. Sculpture of ventral half of posterior mesepimeral area: smooth. Fine setigerous punctures on dorsal half of posterior mesepimeral area: present. Mesopleural carina: present. Setation of ventral metapleural area: absent in area immediately below metapleural sulcus. Setation of metapleural triangle: sparse. Color of legs: yellow throughout.

Color of metasoma: orange to brown. Horn of T1: bulge smooth, at least anteriorly; present as a small bulge. Microsculpture of T2: present. Microsculpture on T3: present. Macrosculpture of T3 medially: reticulate rugose. Macrosculpture of T3 laterally: reticulate rugose. Microsculpture of T4: absent. Macrosculpture of T4 laterally: rugulose. Punctation of T4: dense throughout. Macrosculpture of T5: absent. Punctation of T5: dense throughout. Microsculpture of S3: absent. Macrosculpture of S3 laterally: absent; weakly longitudinally strigose.

Diagnosis. Paridris nephta is best distinguished by the uniform striation of the frons below the median ocellus, absence of microsculpture on the head and the smooth interspaces of the mesoscutellum. Color patterns are highly variable in this species and should be avoided entirely for identification.

\section{Link to Distribution Map. ${ }^{25}$}

Material Examined. Other material: (129 females, 95 males) JAPAN: 73 females, 71 males, OSUC 181186-181189, 181191-181196, 181203-181209, 181213181214, 181216-181218, 181221, 262145-262186, 262194-262199, 262225262233, 262240-262247, 265063-265068, 265070-265071, 265073-265085, 


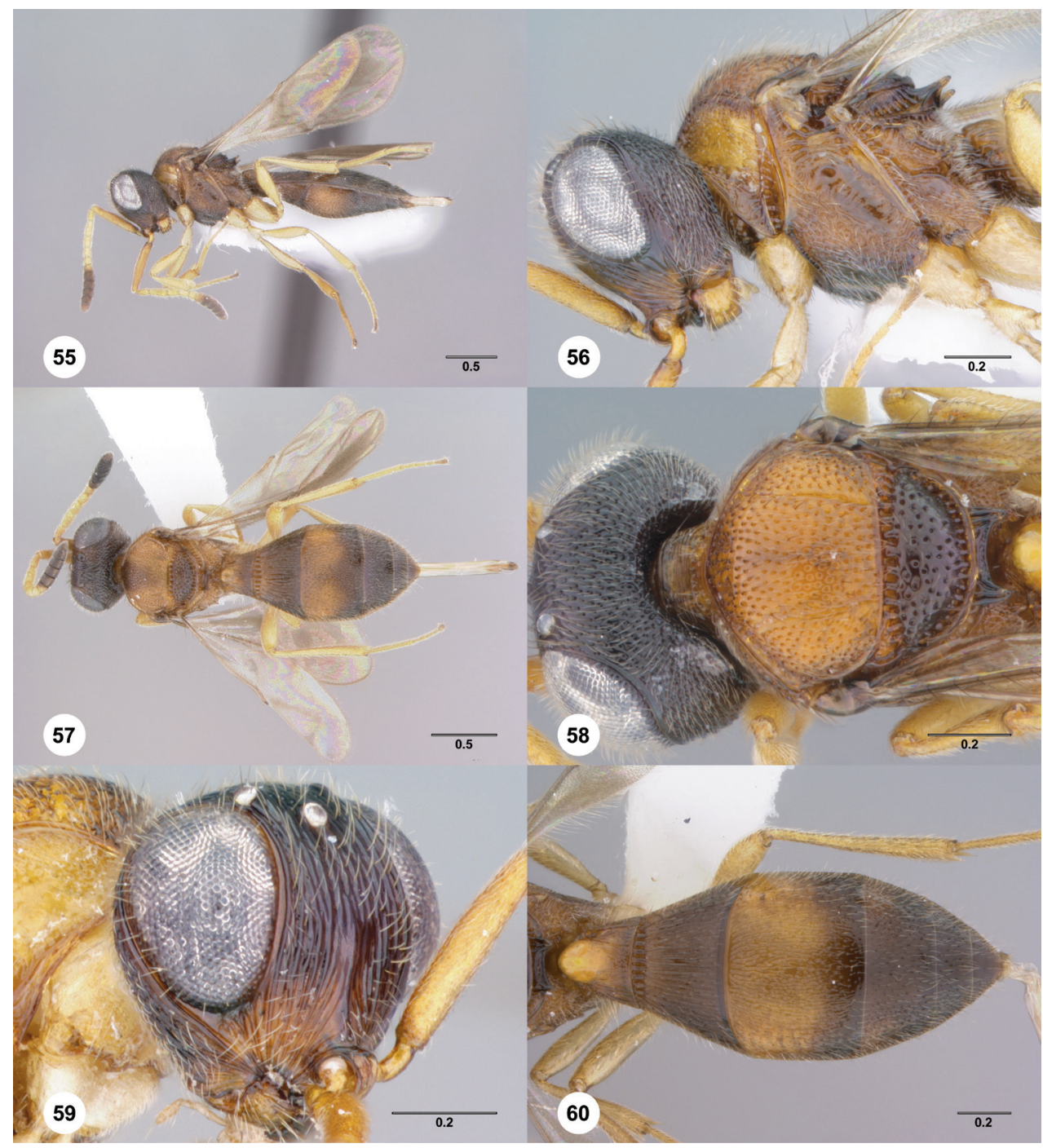

Figures 55-60.71 Paridris nephta 55 Lateral habitus, female (OSUC 265087) 56 Head and mesosoma, lateral view, female (OSUC 265087) 57 Dorsal habitus, female (OSUC 265150). 58, Head and mesosoma, dorsal view, female (OSUC 262229) 59 Head, anterolateral view, female (OSUC 143437) 60 Metasoma, dorsal view, female (OSUC 265195). Scale bars in millimeters.

265087-265089, 265093-265099, 265122-265132, 265134, 265139-265145, 265150-265152, 265155, 265195-265196 (CNCI). RUSSIA: 3 females, 3 males, OSUC 143437, 241513, 241655-241657, 404916 (OSUC). SOUTH KOREA: 53 females, 21 males, OSUC 181190, 181197, 181210, 181215, 181222-181225, 262187-262192, 262210-262219, 262221-262224, 262234, 262248-262258, 262260-262262, 265069, 265100-265121, 265136-265138, 265146-265149, 265197 (CNCI). 


\section{Paridris nilaka Talamas, sp. $\mathbf{n}$.}

urn:lsid:zoobank.org:act:EC0F912C-9AA2-4401-9251-4906A7B2BD1A

urn:Isid:biosci.ohio-state.edu:osuc_concepts:273890

http://species-id.net/wiki/Paridris_nilaka

Figures 13, 61-66, 109; Morphbank ${ }^{26}$

Description. Female body length: $2.60-4.00 \mathrm{~mm}(\mathrm{n}=7)$. Color of head: black throughout. Ventral clypeal margin: serrate. Sculpture of frons medially: smooth. Sculpture of frons immediately ventral of median ocellus: dorsoventrally strigose throughout; rugose. Microsculpture of frons: absent. Sculpture of posterior vertex: punctate rugulose. Sculpture of gena: punctate rugulose. Basiconic sensillum on A7: absent.

Wings: macropterous, apex of forewing extending beyond posterior margin of T3. Length of R1: less than r-rs. Notaulus: percurrent. Color of mesosoma: dark brown to black. Sculpture of mesoscutum medially: densely punctate, with longitudinal rugae in posterior half; areolate rugulose. Sculpture of mesoscutellum: punctate rugulose throughout. Dark bristle-like setae along transverse pronotal carina: absent. Sculpture ventral of transverse pronotal carina: finely punctate. Sculpture of femoral groove: smooth; striate in ventral end. Sculpture of ventral half of posterior mesepimeral area: smooth. Fine setigerous punctures on dorsal half of posterior mesepimeral area: present. Mesopleural carina: present along anterior half of femoral groove. Setation of ventral metapleural area: absent in area immediately below metapleural sulcus. Setation of metapleural triangle: dense. Color of legs: yellow throughout.

Color of metasoma: dark brown to black throughout. Horn of T1: bulge smooth, at least anteriorly; absent. Microsculpture of T2: absent. Microsculpture on T3: present. Macrosculpture of T3 medially: weakly longitudinally strigose. Macrosculpture of T3 laterally: reticulate rugose; longitudinally strigose. Microsculpture of T4: absent. Macrosculpture of T4 laterally: rugulose. Punctation of T4: sparse along midline, otherwise dense; dense throughout; moderately dense throughout. Macrosculpture of T5: absent; rugulose laterally. Punctation of T5: dense throughout; sparse medially, dense laterally. Microsculpture of S3: absent. Macrosculpture of S3 laterally: absent.

Diagnosis. The rugulose sculpture of the dorsal mesoscutum and mesoscutellum in P. nilaka is shared with $P$. rugulosus and $P$. toketoki; it may be separated from both by the dense, fine setation of the pronotal shoulder. Additionally, the typically black color of the body may be useful for identification, but should be used with caution given the color plasticity seen in many species.

Etymology. The epithet "nilaka" means "black" in Thai, and is used as a noun in apposition.

\section{Link to Distribution Map. ${ }^{27}$}




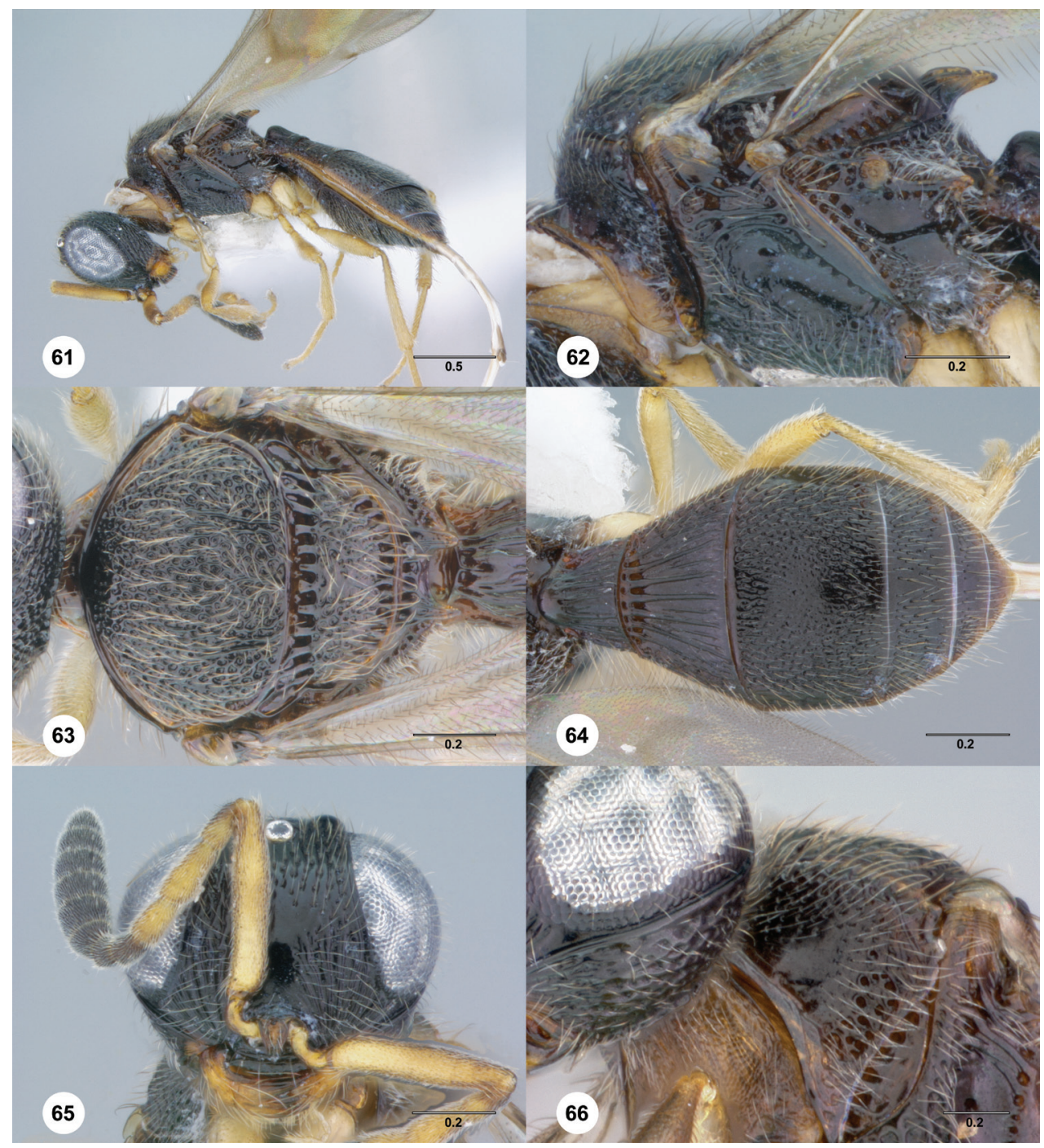

Figures 6I-66. ${ }^{72}$ Paridris nilaka sp. n. 6 I Lateral habitus, female holotype (OSUC 266165) 62 Mesosoma, lateral view, female holotype (OSUC 266165) 63 Mesosoma, dorsal view, female (OSUC 254613). 64, Metasoma, dorsal view, female holotype (OSUC 266165) 65 Head, anterior view, female holotype (OSUC 266165) 66 Pronotum, anterolateral view, female (OSUC 334223). Scale bars in millimeters.

Material Examined. Holotype, female: THAILAND: Chiang Mai Prov., checkpoint 2, T1909, Doi Inthanon National Park, $18^{\circ} 31.554^{\prime} \mathrm{N} 98^{\circ} 29.940^{\prime} \mathrm{E}, 1700 \mathrm{~m}$, 14.XI-15.XI.2006, pan trap, Y. Areeluck, OSUC 266165 (deposited in QSBG). Paratypes: THAILAND: 6 females, OSUC 334247 (CNCI); OSUC 254613, 381811 (OSUC); OSUC 334223, 334295, 396843 (QSBG). 


\section{Paridris reptilis Talamas, sp. $\mathbf{n}$.}

urn:Isid:zoobank.org:act:519CC4FD-EC66-48EA-9652-ECB6FDF14FC9

urn:lsid:biosci.ohio-state.edu:osuc_concepts:273878

http://species-id.net/wiki/Paridris_reptilis

Figures 67-72; Morphbank ${ }^{28}$

Description. Female body length: $2.35-2.40 \mathrm{~mm}(\mathrm{n}=2)$. Color of head: reddish brown. Ventral clypeal margin: serrate. Sculpture of frons medially: mostly smooth with faint dorsoventral striation. Sculpture of frons immediately ventral of median ocellus: dorsoventrally strigose laterally. Microsculpture of frons: absent. Sculpture of posterior vertex: irregularly rugulose. Sculpture of gena: irregularly rugulose. Basiconic sensillum on A7: absent.

Wings: brachypterous, apex of forewing ending before T4. Notaulus: percurrent. Color of mesosoma: variably yellow to brown. Sculpture of mesoscutum medially: areolate rugulose. Sculpture of mesoscutellum: areolate rugulose. Dark bristlelike setae along transverse pronotal carina: absent. Sculpture ventral of transverse pronotal carina: rugulose posteriorly. Sculpture of femoral groove: striate in ventral end. Sculpture of ventral half of posterior mesepimeral area: smooth. Fine setigerous punctures on dorsal half of posterior mesepimeral area: present. Mesopleural carina: present. Setation of ventral metapleural area: absent in area immediately below metapleural sulcus. Setation of metapleural triangle: moderately dense. Color of legs: yellow throughout.

Color of metasoma: reddish brown. Horn of T1: bulge smooth, at least anteriorly; absent. Microsculpture of T2: present. Microsculpture on T3: absent. Macrosculpture of T3 medially: longitudinally strigose. Macrosculpture of T3 laterally: longitudinally strigose. Microsculpture of T4: absent. Macrosculpture of T4 laterally: rugulose. Punctation of T4: sparse along midline, otherwise dense. Macrosculpture of T5: absent. Punctation of T5: moderately dense throughout. Microsculpture of S3: absent. Macrosculpture of S3 laterally: absent.

Diagnosis. Paridris reptilis and $P$. ferus are the only known brachypterous species in the P. nephta group. Paridris ferus has a basiconic sensillum on A7 and lacks interstitial microsculpture on T2. Paridris reptilis does not have a sensillum on A7 and T2 is densely microsculptured.

Etymology. The adjectival epithet "reptilis", meaning "crawling" in Latin, refers to the reduced wing size in this species.

Link to Distribution Map. ${ }^{29}$

Material Examined. Holotype, female: TAIWAN: Taiwan Prov., Pingtung Co., Kuai-Ku Hut, T-103, Pei-ta-wu (Peitawushan) Mountain, 2125m, 26.IV-30.IV.1992, A. Smetana, OSUC 181211 (deposited in CNCI). Paratype: TAIWAN: 1 female, OSUC 265153 (CNCI). 


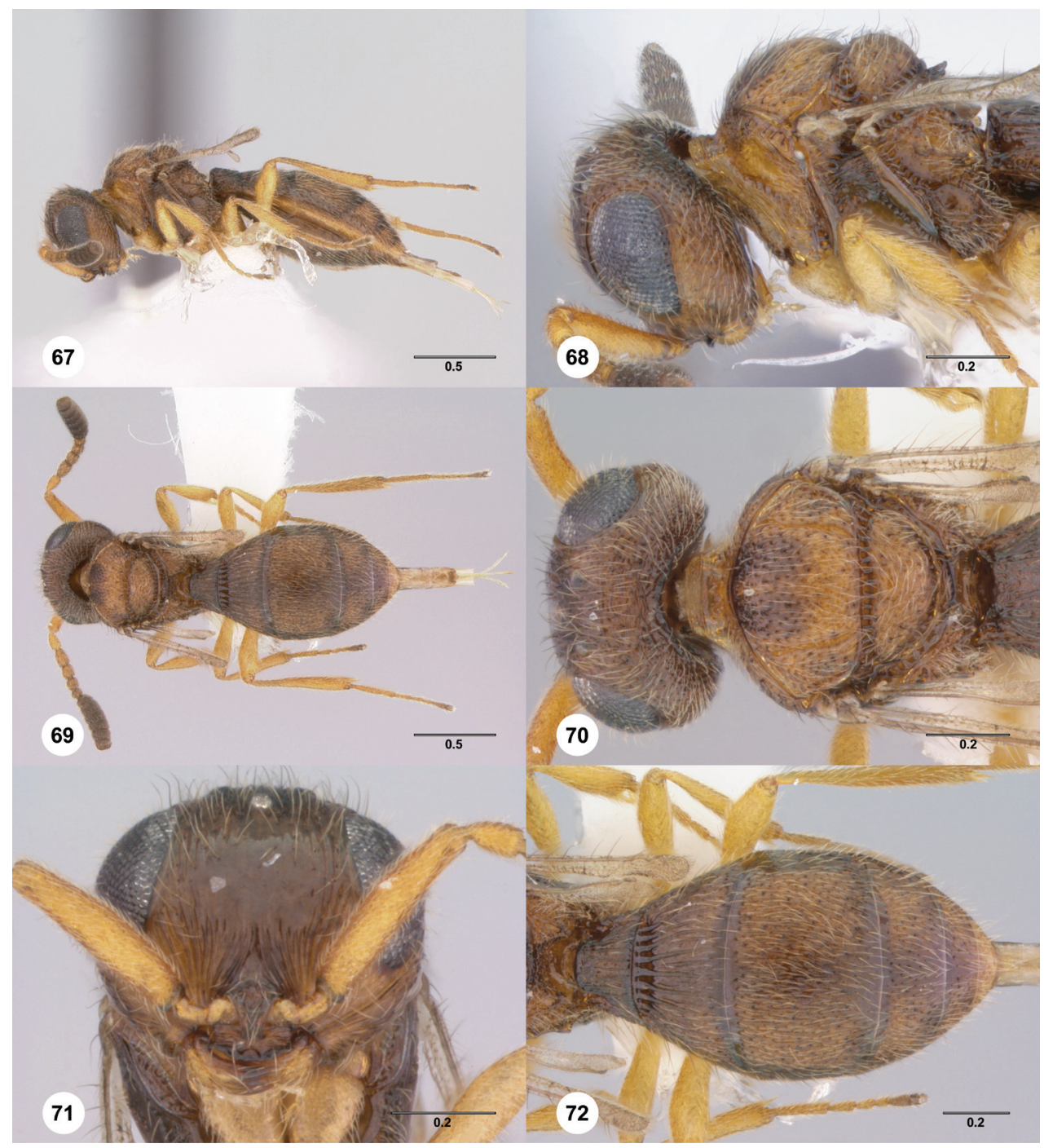

Figures 67-72. ${ }^{73}$ Paridris reptilis sp. n., female holotype (OSUC 181211) 67 Lateral habitus 68 Head and mesosoma, lateral view 69 Dorsal habitus $\mathbf{7 0}$ Head and mesosoma, dorsal view 7I Head, anterior view 72 Metasoma, dorsal view. Scale bars in millimeters. 


\section{Paridris rugulosus Talamas, sp. n.}

urn:lsid:zoobank.org:act:8B3B767C-6BC7-40D8-B531-9DD8ED1B57EF

urn:lsid:biosci.ohio-state.edu:osuc_concepts:273914

http://species-id.net/wiki/Paridris_rugulosus

Figures 73-78; Morphbank ${ }^{30}$

Description. Female body length: $2.48-2.56 \mathrm{~mm}(\mathrm{n}=2)$. Color of head: yellow, becoming darker dorsally; black throughout. Ventral clypeal margin: serrate. Sculpture of frons medially: smooth. Sculpture of frons immediately ventral of median ocellus: dorsoventrally strigose laterally; dorsoventrally strigose throughout. Microsculpture of frons: absent. Sculpture of posterior vertex: irregularly rugulose; punctate rugulose. Sculpture of gena: irregularly rugulose. Basiconic sensillum on A7: absent.

Wings: macropterous, apex of forewing extending beyond posterior margin of T3. Length of R1: equal to r-rs. Notaulus: percurrent. Color of mesosoma: variably yellow to brown. Sculpture of mesoscutum medially: areolate rugulose. Sculpture of mesoscutellum: punctate rugulose throughout; areolate rugulose. Dark bristlelike setae along transverse pronotal carina: present. Sculpture ventral of transverse pronotal carina: smooth. Sculpture of femoral groove: smooth; striate in ventral end. Sculpture of ventral half of posterior mesepimeral area: smooth. Fine setigerous punctures on dorsal half of posterior mesepimeral area: absent. Mesopleural carina: present. Setation of ventral metapleural area: absent in area immediately below metapleural sulcus. Setation of metapleural triangle: sparse. Color of legs: yellow throughout.

Color of metasoma: reddish brown. Horn of T1: absent. Microsculpture of T2: absent. Microsculpture on T3: absent. Macrosculpture of T3 medially: weakly longitudinally strigose. Macrosculpture of T3 laterally: longitudinally strigose. Microsculpture of T4: absent. Macrosculpture of T4 laterally: weakly rugulose. Punctation of T4: moderately dense throughout. Macrosculpture of T5: absent. Punctation of T5: moderately dense throughout. Microsculpture of S3: absent. Macrosculpture of S3 laterally: absent.

Diagnosis. Paridris rugulosus is most similar to P. toketoki and may be separated by the smooth surface of the lateral pronotum.

Etymology. The Latin adjectival epithet "rugulosus" refers to the rugulose sculpture of the head and dorsal mesosoma in this species.

Link to Distribution Map. ${ }^{31}$

Material Examined. Holotype, female: VIETNAM: Vinh Phuc Prov., Tam Dao, 1050-1175m, 14.VI-17.VI.2007, malaise trap, C. v. Achterberg \& R. de Vries, OSUC 265238 (deposited in RMNH). Paratype: LAOS: 1 female, OSUC 262200 (CNCI). 


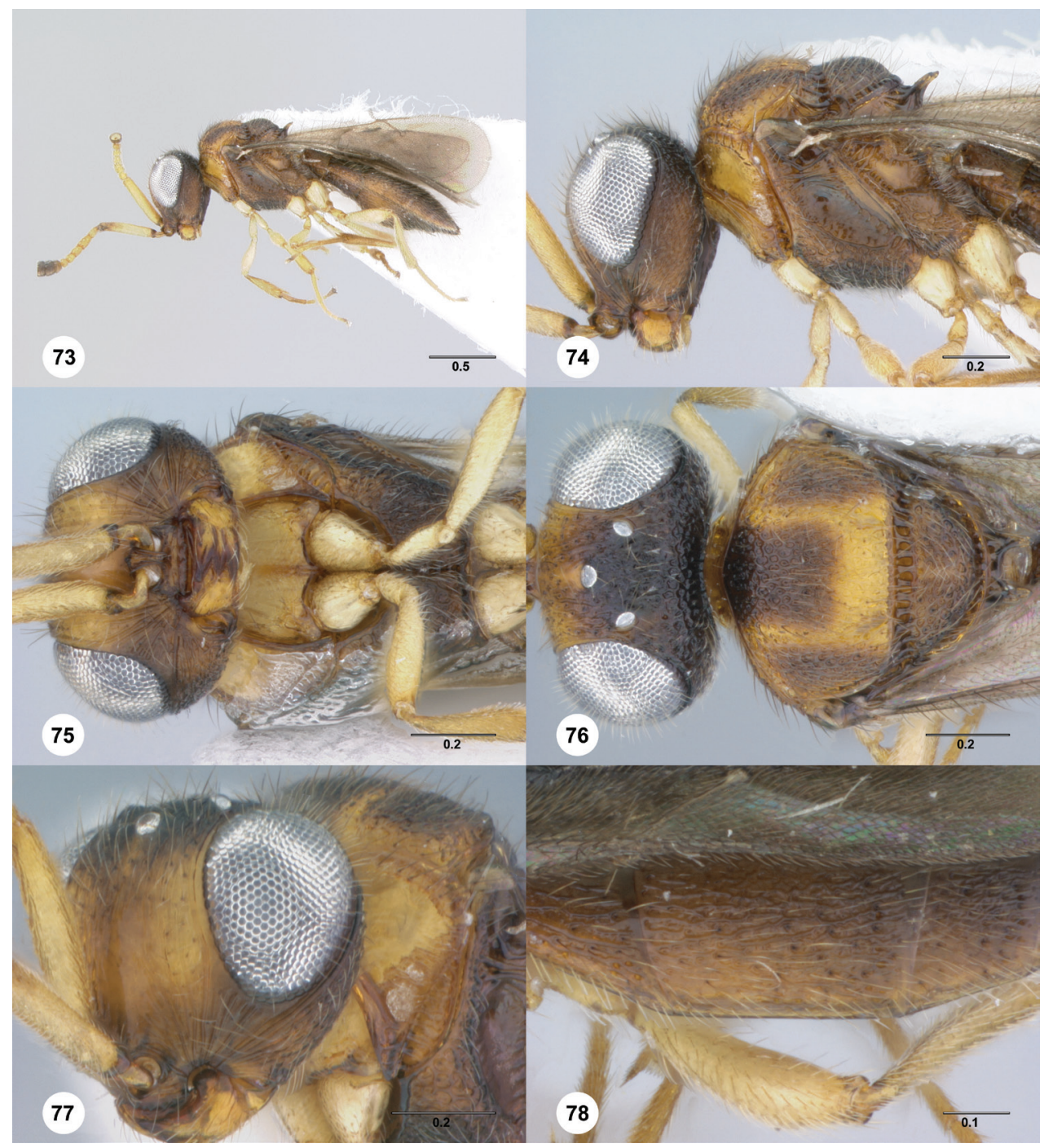

Figures 73-78. ${ }^{74}$ Paridris rugulosus sp. n., female holotype (OSUC 265238) 73 Lateral habitus 74 Head and mesosoma, lateral view $\mathbf{7 5} \mathrm{Head}$ and mesosoma, ventral view $\mathbf{7 6} \mathrm{Head}$ and mesosoma, dorsal view 77 Head and pronotum, anterolateral view 78 T2-T4, dorsolateral view. Scale bars in millimeters. 


\section{Paridris solaris Talamas, sp. $\mathbf{n}$.}

urn:lsid:zoobank.org:act:B2878DA2-1E8F-4B6E-96C4-86B571C11F04

urn:lsid:biosci.ohio-state.edu:osuc_concepts:241280

http://species-id.net/wiki/Paridris_solaris

Figures 79-84, 110; Morphbank ${ }^{32}$

Description. Female body length: $1.96-3.43 \mathrm{~mm}(\mathrm{n}=19)$. Color of head: reddish brown; orange throughout; dark brown to black; yellow. Ventral clypeal margin: serrate. Sculpture of frons medially: smooth. Sculpture of frons immediately ventral of median ocellus: dorsoventrally strigose throughout; rugose. Microsculpture of frons: absent. Sculpture of posterior vertex: finely punctate; moderately punctate; punctate rugulose. Sculpture of gena: punctate rugulose. Basiconic sensillum on A7: absent.

Wings: macropterous, apex of forewing extending beyond posterior margin of T3. Length of R1: equal to r-rs; longer than r-rs. Notaulus: percurrent. Color of mesosoma: variably orange to brown; yellow throughout; orange throughout. Sculpture of mesoscutum medially: densely punctate, with longitudinal rugae in posterior half; densely punctate throughout. Sculpture of mesoscutellum: smooth medially, moderately punctate laterally; densely punctate. Dark bristlelike setae along transverse pronotal carina: absent. Sculpture ventral of transverse pronotal carina: finely punctate. Sculpture of femoral groove: smooth; striate in ventral end. Sculpture of ventral half of posterior mesepimeral area: smooth. Fine setigerous punctures on dorsal half of posterior mesepimeral area: present. Mesopleural carina: present. Setation of ventral metapleural area: absent in area immediately below metapleural sulcus. Setation of metapleural triangle: dense; moderately dense; sparse. Color of legs: yellow throughout.

Color of metasoma: yellow; orange to brown. Horn of T1: bulge smooth, at least anteriorly; absent. Microsculpture of T2: absent. Microsculpture on T3: absent. Macrosculpture of T3 medially: longitudinally strigose; weakly longitudinally strigose. Macrosculpture of T3 laterally: longitudinally strigose. Microsculpture of T4: absent. Macrosculpture of T4 laterally: absent. Punctation of T4: dense throughout. Macrosculpture of T5: absent. Punctation of T5: dense throughout; moderately dense throughout. Microsculpture of S3: absent. Macrosculpture of S3 laterally: weakly longitudinally strigose.

Diagnosis. Paridris solaris is most similar to P. minator. It may be separated from it by the absence of a basiconic sensillum on A7.

Etymology. The adjectival epithet "solaris" means "of the sun" in Latin and references the bright yellow-orange color present in many individuals of this species.

\section{Link to Distribution Map. ${ }^{33}$}

Material Examined. Holotype, female: VIETNAM: Thua Thien-Hue Prov., $\sim 1.5 \mathrm{~km} \mathrm{NE}$ along trail behind upper guesthouse, light gap / semi-tropical evergreen forest, ROM 2000512, Bach Ma National Park, 16¹1'50.3"N 107²51'17.7"E, 1200m, 6.VI-17.VI.2000, malaise trap/pan trap, B. Hubley, OSUC 240944 (deposited in ROME). Paratypes: (21 females) LAOS: 3 females, OSUC 334242-334243, 


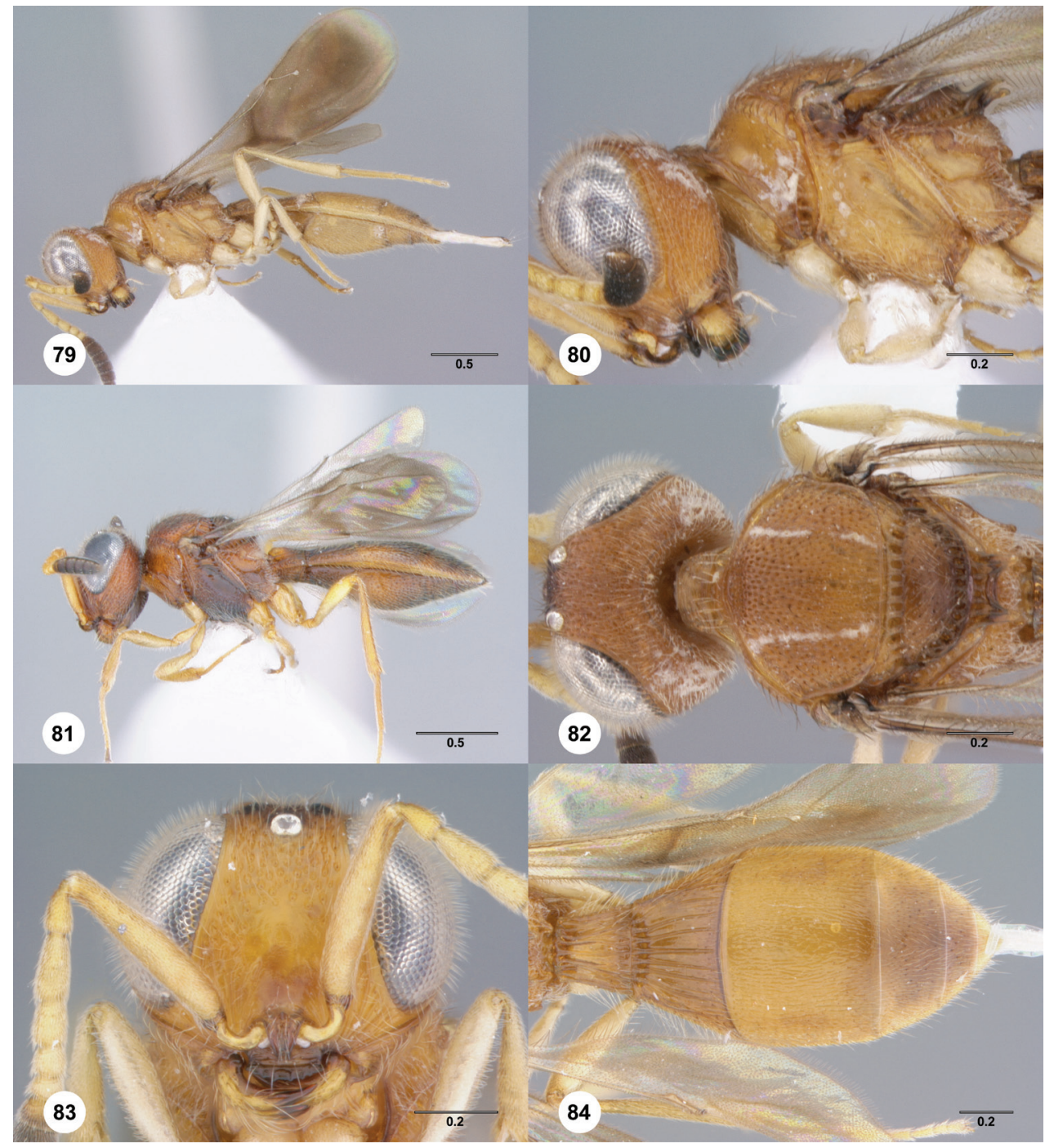

Figures 79-84. ${ }^{75}$ Paridris solaris sp. n. 79 Lateral habitus, female holotype (OSUC 240944) 80 Head and mesosoma, lateral view, female holotype (OSUC 240944) 8I Lateral habitus, female (OSUC 237532). 82, Head and mesosoma, dorsal view, female holotype (OSUC 240944) 83 Head, anterior view, female (OSUC 240948) 84 Metasoma, dorsal view, female (OSUC 240946). Scale bars in millimeters.

334248 (CNCI). THAILAND: 5 females, OSUC 334144, 396849 (OSUC); OSUC 237532, 265212, 334207 (QSBG). VIETNAM: 13 females, OSUC 240940 (IEBR); OSUC 240945, 404917-404918 (OSUC); OSUC 265234-265236, 277369, 281520 (RMNH); OSUC 240946, 240948, 266180, 404919 (ROME).

Comments. The color of specimens of $P$. solaris varies significantly according to geographical location. Those from Vietnam are typically yellow throughout (Fig. 79) and those from Thailand are variably orange, red, and black (Fig. 81). 


\section{Paridris teres Talamas, sp. n.}

urn:lsid:zoobank.org:act:8A24D695-8FC0-4921-8885-B8FC3493FBE3

urn:lsid:biosci.ohio-state.edu:osuc_concepts:273893

http://species-id.net/wiki/Paridris_teres

Figures 85-90; Morphbank ${ }^{34}$

Description. Female body length: $2.42 \mathrm{~mm}(\mathrm{n}=1)$. Color of head: yellow. Ventral clypeal margin: smooth. Sculpture of frons medially: smooth. Sculpture of frons immediately ventral of median ocellus: dorsoventrally strigose throughout. Microsculpture of frons: absent. Sculpture of posterior vertex: punctate rugulose. Sculpture of gena: punctate rugulose. Basiconic sensillum on A7: absent.

Wings: macropterous, apex of forewing extending beyond posterior margin of T3. Length of R1: equal to r-rs. Notaulus: percurrent. Color of mesosoma: yellow throughout. Sculpture of mesoscutum medially: densely punctate, with longitudinal rugae in posterior half. Sculpture of mesoscutellum: smooth along midline, otherwise punctate rugulose. Dark bristlelike setae along transverse pronotal carina: absent. Sculpture ventral of transverse pronotal carina: finely punctate. Sculpture of ventral half of posterior mesepimeral area: smooth. Fine setigerous punctures on dorsal half of posterior mesepimeral area: present. Mesopleural carina: present. Setation of ventral metapleural area: absent in area immediately below metapleural sulcus. Setation of metapleural triangle: moderately dense. Color of legs: yellow throughout.

Color of metasoma: yellow. Horn of T1: absent. Microsculpture of T2: absent. Microsculpture on T3: present. Macrosculpture of T3 medially: absent. Macrosculpture of T3 laterally: absent. Microsculpture of T4: absent. Macrosculpture of T4 laterally: weakly rugulose. Punctation of T4: dense throughout. Macrosculpture of T5: rugulose laterally. Punctation of T5: moderately dense throughout. Microsculpture of S3: absent. Macrosculpture of S3 laterally: weakly longitudinally strigose.

Diagnosis. Paridris teres may be easily identified by the smooth ventral margin of the clypeus.

Etymology. The epithet "teres", meaning smooth in Latin, refers to the smooth margin of the clypeus and is used as a noun in apposition.

\section{Link to Distribution Map. ${ }^{35}$}

Material Examined. Holotype, female: VIETNAM: Vinh Phuc Prov., Tam Dao, 1050-1175m, 14.VI-17.VI.2007, malaise trap, C. v. Achterberg \& R. de Vries, OSUC 265237 (deposited in RMNH).

Comments. The sole specimen of this species was damaged during examination after it was imaged. The head, propleuron and forelegs are now mounted on the point separate from the remainder of the body; A7-12 of the right antenna are lost. 


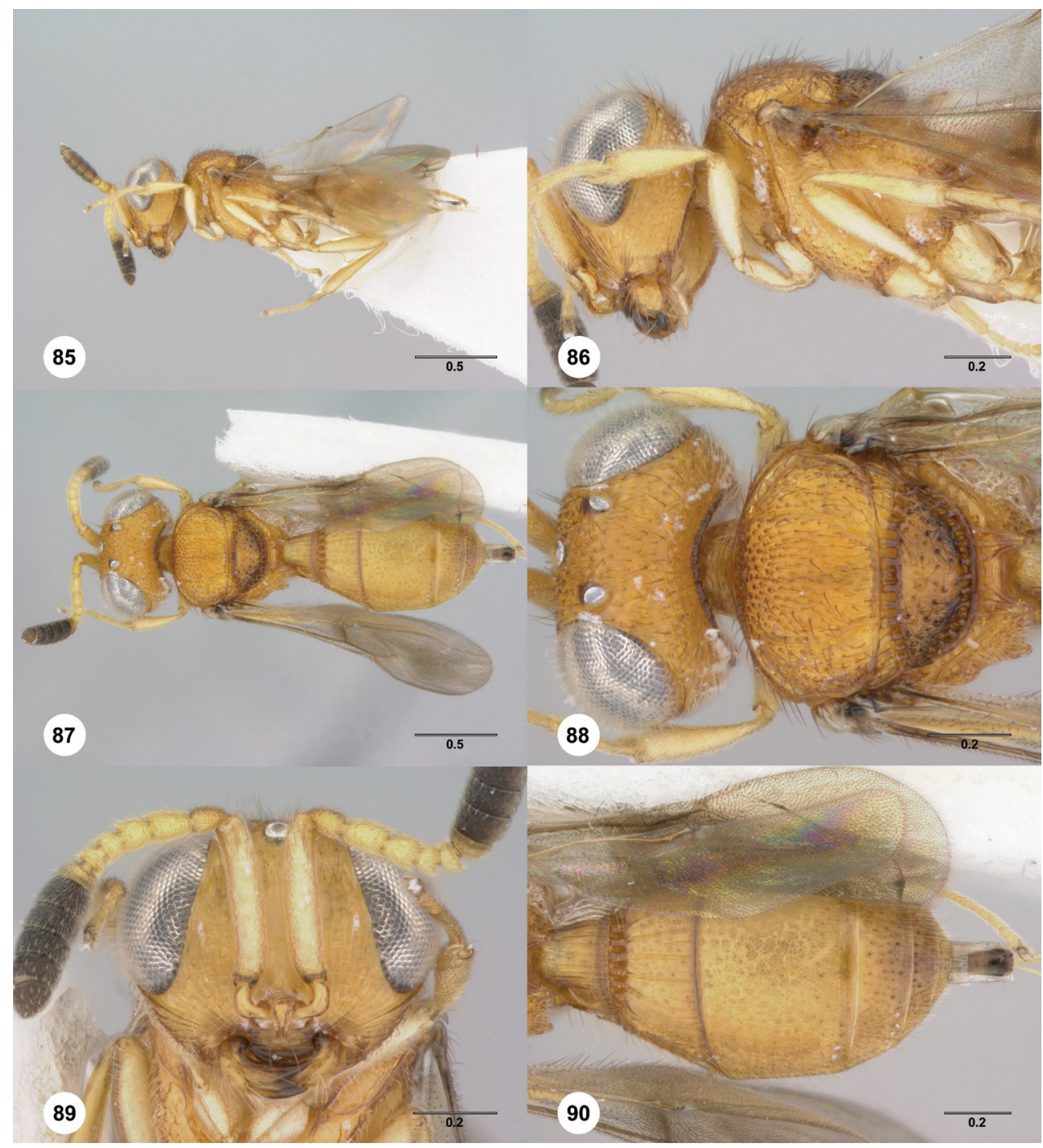

Figures 85-90.76 Paridris teres sp. n., female holotype (OSUC 265237) 85 Lateral habitus $\mathbf{8 6}$ Head and mesosoma, lateral view $\mathbf{8 7}$ Dorsal habitus $\mathbf{8 8} \mathrm{Head}$ and mesosoma, dorsal view $\mathbf{8 9}$ Head, anterior view 90 Metasoma, dorsal view. Scale bars in millimeters. 


\section{Paridris toketoki Talamas, sp. n.}

urn:Isid:zoobank.org:act:628BBEF3-C3BA-4EE4-A905-3334CBD8ED7F

urn:lsid:biosci.ohio-state.edu:osuc_concepts:273915

http://species-id.net/wiki/Paridris_toketoki

Figures 91-96; Morphbank ${ }^{36}$

Description. Female body length: $2.54 \mathrm{~mm}(\mathrm{n}=1)$. Color of head: dark orange, becoming brown at vertex. Ventral clypeal margin: serrate. Sculpture of frons medially: smooth. Sculpture of frons immediately ventral of median ocellus: dorsoventrally strigose laterally. Microsculpture of frons: absent. Sculpture of posterior vertex: punctate rugulose. Sculpture of gena: punctate rugulose. Basiconic sensillum on A7: absent.

Wings: macropterous, apex of forewing extending beyond posterior margin of T3. Length of R1: less than r-rs. Notaulus: smooth furrow incomplete, reaching suprahumeral sulcus as row of punctures. Color of mesosoma: variably orange to brown. Sculpture of mesoscutum medially: densely punctate throughout. Sculpture of mesoscutellum: punctate rugulose throughout. Dark bristlelike setae along transverse pronotal carina: present. Sculpture ventral of transverse pronotal carina: finely punctate. Sculpture of femoral groove: smooth. Sculpture of ventral half of posterior mesepimeral area: smooth. Fine setigerous punctures on dorsal half of posterior mesepimeral area: present. Mesopleural carina: present along anterior half of femoral groove. Setation of ventral metapleural area: absent in area immediately below metapleural sulcus. Setation of metapleural triangle: moderately dense. Color of legs: yellow throughout.

Color of metasoma: orange to brown. Horn of T1: bulge smooth, at least anteriorly. Microsculpture of T2: absent. Microsculpture on T3: uncertain, absent. Macrosculpture of T3 medially: weakly longitudinally strigose. Macrosculpture of T3 laterally: longitudinally rugulose. Microsculpture of T4: absent. Macrosculpture of T4 laterally: rugulose. Punctation of T4: dense throughout. Macrosculpture of T5: rugulose laterally. Punctation of T5: sparse medially, dense laterally. Microsculpture of S3: absent. Macrosculpture of S3 laterally: weakly longitudinally strigose.

Diagnosis. Paridris toketoki is most similar to P. rugulosus. It differs most conspicuously in having the lateral face of the pronotum densely punctate along its dorsal margin.

Etymology. This species is named for the great Paiwan chief, Toketok.

Link to Distribution Map. ${ }^{37}$

Material Examined. Holotype, female: TAIWAN: Taiwan Prov., Nantou Co., Jihyüeh (Sun Moon) Lake, H025, Te-hua-she (Tehuache), 800m, 5.VI.1980, J. Heraty, OSUC 181200 (deposited in CNCI). 


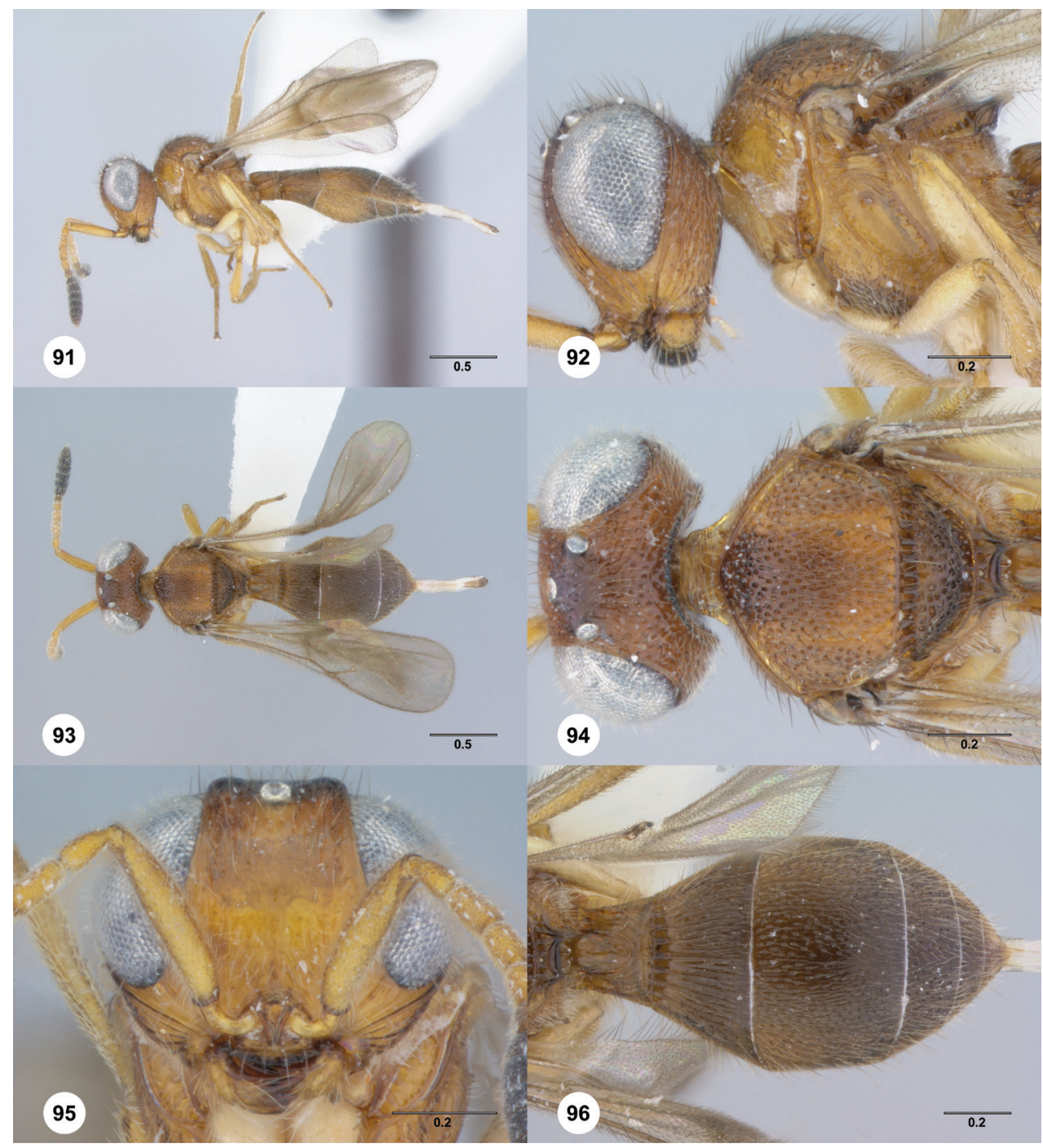

Figures 9 I-96. ${ }^{77}$ Paridris toketoki sp. n., female holotype (OSUC 181200) 9 I Lateral habitus 92 Head and mesosoma, lateral view $\mathbf{9 3}$ Dorsal habitus $\mathbf{9 4}$ Head and mesosoma, dorsal view 95 Head, anterior view 96 Metasoma, dorsal view. Scale bars in millimeters. 


\section{Paridris verrucosus Talamas, sp. $\mathrm{n}$.}

urn:Isid:zoobank.org:act:CCEB3258-CADF-4F0F-B2E2-983F94AF5372

urn:lsid:biosci.ohio-state.edu:osuc_concepts:275741

http://species-id.net/wiki/Paridris_verrucosus

Figures 17, 97-102; Morphbank ${ }^{38}$

Description. Female body length: $1.97 \mathrm{~mm}(\mathrm{n}=1)$. Color of head: dark brown to black. Ventral clypeal margin: serrate. Sculpture of frons medially: smooth. Sculpture of frons immediately ventral of median ocellus: dorsoventrally strigose throughout. Microsculpture of frons: uncertain, absent. Sculpture of posterior vertex: irregularly rugulose. Sculpture of gena: irregularly rugulose. Basiconic sensillum on A7: absent.

Wings: macropterous, apex of forewing extending beyond posterior margin of T3. Length of R1: equal to r-rs. Notaulus: absent. Color of mesosoma: variably orange to brown. Sculpture of mesoscutum medially: areolate rugulose. Sculpture of mesoscutellum: areolate rugulose. Dark bristlelike setae along transverse pronotal carina: present. Sculpture ventral of transverse pronotal carina: rugulose posteriorly. Sculpture of femoral groove: striate below mesopleural pit. Sculpture of ventral half of posterior mesepimeral area: rugulose. Fine setigerous punctures on dorsal half of posterior mesepimeral area: absent. Mesopleural carina: present. Setation of ventral metapleural area: absent in area immediately below metapleural sulcus. Setation of metapleural triangle: moderately dense. Color of legs: yellow throughout.

Color of metasoma: reddish brown. Horn of T1: absent. Microsculpture of T2: present. Microsculpture on T3: present. Macrosculpture of T3 medially: reticulate. Macrosculpture of T3 laterally: longitudinally rugulose. Microsculpture of T4: present. Macrosculpture of T4 laterally: rugulose. Punctation of T4: moderately dense throughout. Macrosculpture of T5: rugulose laterally. Punctation of T5: moderately dense laterally and along anterior margin. Microsculpture of S3: present. Macrosculpture of S3 laterally: longitudinally strigose.

Diagnosis. Paridris verrucosus is the only species in the P. nephta group with microsculpture on S3.

Etymology. The adjectival epithet "verrucosus" means "full of warts" in Latin; it is given to this species for the dense microsculpture of the metasoma.

\section{Link to Distribution Map. ${ }^{39}$}

Material Examined. Holotype, female: CHINA: Guangdong Prov., creek, Nankunshan, $23^{\circ} 37.287^{\prime} \mathrm{N} 113^{\circ} 51.267^{\prime} \mathrm{S}, 581 \mathrm{~m}, 29 . \mathrm{X}-31 . \mathrm{X} .2009$, yellow pan trap, L. Masner, OSUC 334249 (deposited in CNCI). 


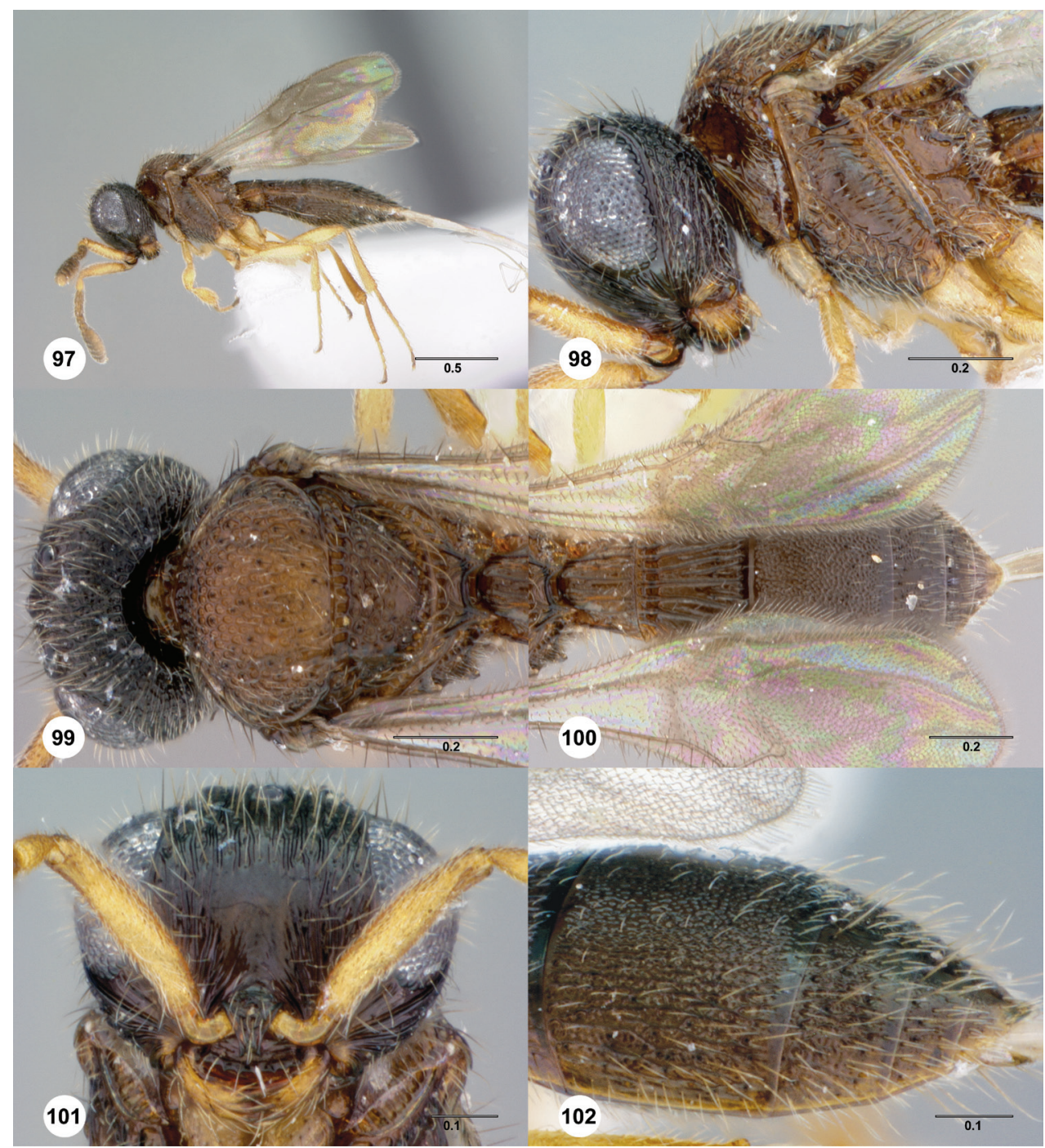

Figures 97-102. ${ }^{78}$ Paridris verrucosus sp. n., female holotype (OSUC 334249) 97 Lateral habitus 98 Head and mesosoma, lateral view 99 Head and mesosoma, dorsal view 100 Metasoma, dorsal view I0 I Head, anterior view 102 T3-T6, dorsolateral view. Scale bars in millimeters. 


\section{Paridris yak Talamas, sp. $\mathrm{n}$.}

urn:lsid:zoobank.org:act:37D0E197-226E-4EB5-B367-76F0C5D46276

urn:lsid:biosci.ohio-state.edu:osuc_concepts:241283

http://species-id.net/wiki/Paridris_yak

Figures 15, 103-108; Morphbank ${ }^{40}$

Description. Female body length: $4.15-4.16 \mathrm{~mm}(\mathrm{n}=3)$. Color of head: dark orange, becoming brown at vertex. Ventral clypeal margin: serrate. Sculpture of frons medially: smooth. Sculpture of frons immediately ventral of median ocellus: rugose. Microsculpture of frons: absent. Sculpture of posterior vertex: areolate rugulose. Sculpture of gena: punctate rugulose. Basiconic sensillum on A7: absent.

Wings: macropterous, apex of forewing extending beyond posterior margin of T3. Length of R1: equal to r-rs; less than r-rs. Notaulus: absent; indicated only at posterior margin of mesoscutum. Color of mesosoma: orange to dark red anteriorly, brown posteriorly, mesoscutellum black; variably red to black. Sculpture of mesoscutum medially: areolate rugulose. Sculpture of mesoscutellum: areolate rugulose. Dark bristlelike setae along transverse pronotal carina: absent. Sculpture ventral of transverse pronotal carina: finely punctate. Sculpture of femoral groove: smooth. Sculpture of ventral half of posterior mesepimeral area: smooth. Fine setigerous punctures on dorsal half of posterior mesepimeral area: present. Mesopleural carina: present. Setation of ventral metapleural area: absent in area immediately below metapleural sulcus. Setation of metapleural triangle: moderately dense. Color of legs: yellow throughout.

Color of metasoma: orange to black. Horn of T1: bulge smooth, at least anteriorly. Microsculpture of T2: absent. Microsculpture on T3: absent. Macrosculpture of T3 medially: longitudinally strigose; weakly longitudinally strigose. Macrosculpture of T3 laterally: longitudinally strigose. Microsculpture of T4: absent. Macrosculpture of T4 laterally: rugulose. Punctation of T4: dense throughout. Macrosculpture of T5: rugulose laterally. Punctation of T5: dense throughout. Microsculpture of S3: absent. Macrosculpture of S3 laterally: absent.

Diagnosis. Paridris yak is a large distinctive species best identified by its reduced or absent notaulus, dorsally rugose frons and dorsally pointed axillular carina.

Etymology. The word "yak" is Thai for a mythological ogre. It is treated as a noun in apposition.

\section{Link to Distribution Map. ${ }^{41}$}

Material Examined. Holotype, female: THAILAND: Trang Prov., forest research center, Khao Chong Mountain, $07^{\circ} 33.2^{\prime} \mathrm{N} 99^{\circ} 47.22^{\prime} \mathrm{E}, 75 \mathrm{~m}$, XI-2005, malaise trap, D. Lohman, OSUC 237530 (deposited in QSBG). Paratypes: THAILAND: 3 females, OSUC 396848 (OSUC); OSUC 266085, 334214 (QSBG). 


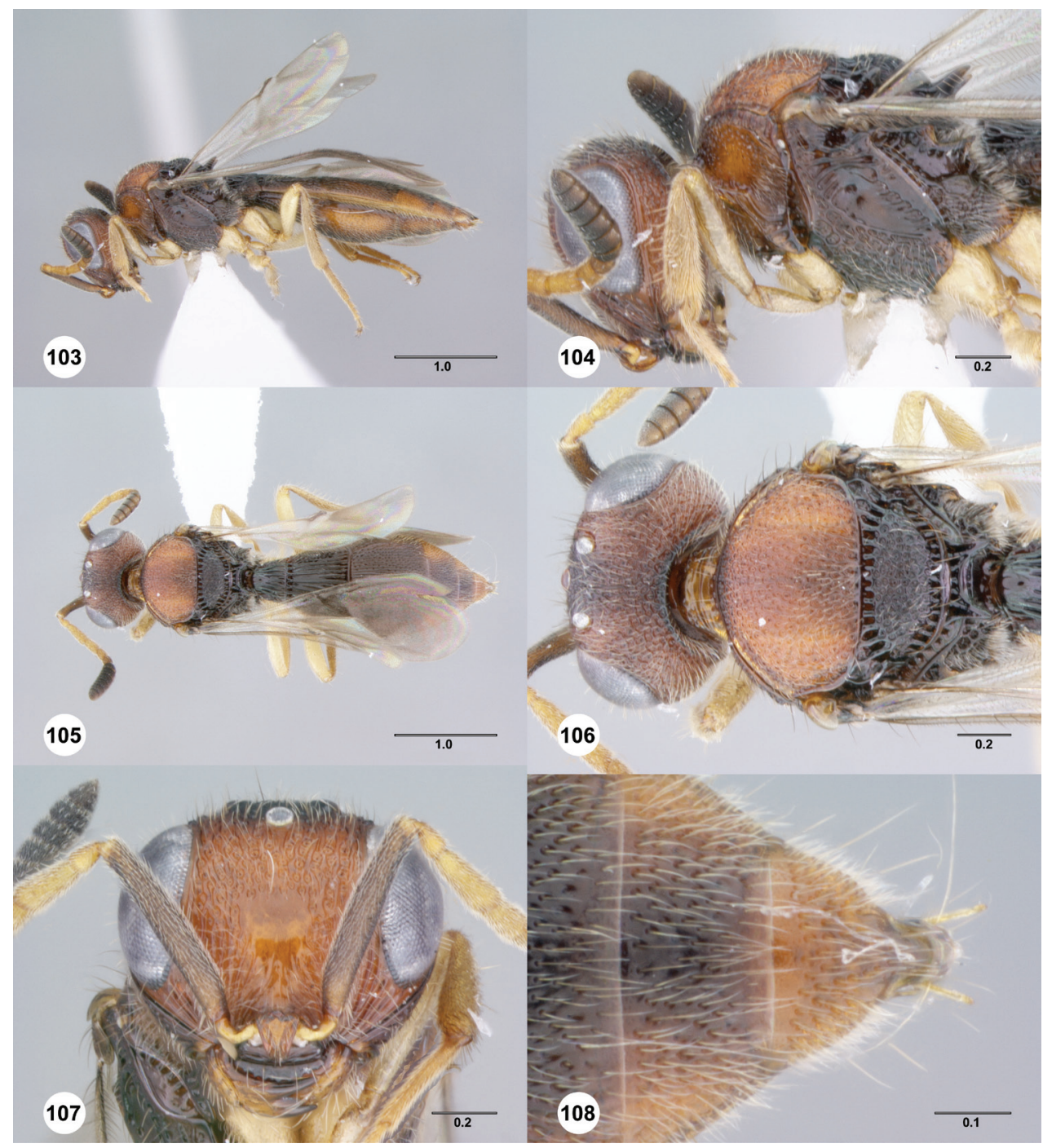

Figures I 03-I 08. ${ }^{79}$ Paridris yak sp. n., female holotype (OSUC 237530) I 03 Lateral habitus 104 Head and mesosoma, lateral view 105 Dorsal habitus 106 Head and mesosoma, dorsal view 107 Head, anterior view 108 T5-T6, dorsal view. Scale bars in millimeters. 


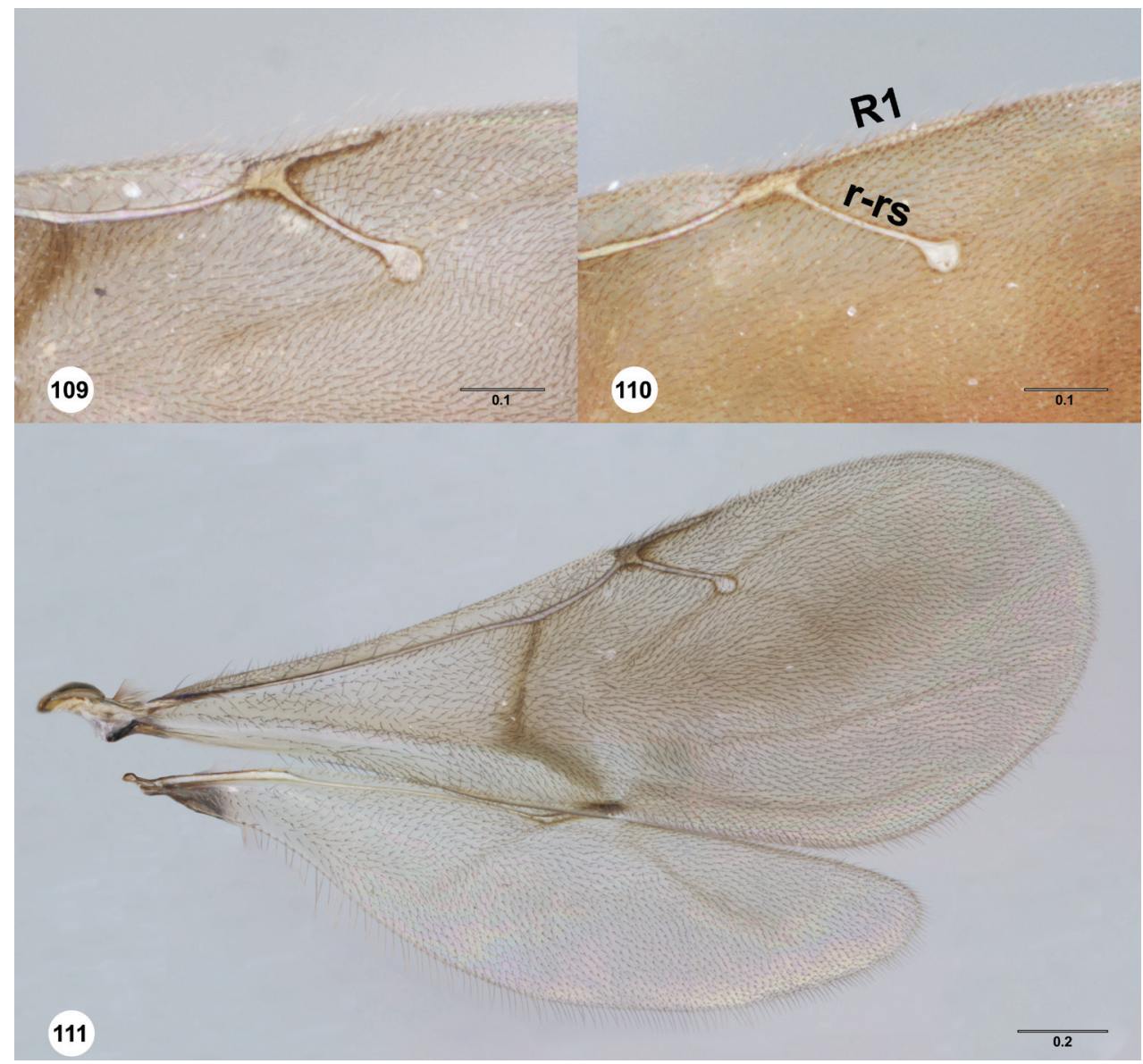

Figures 109-III.$^{80} \mathbf{1 0 9}$ Paridris nilaka sp. n., R1 (postmarginal vein) and r-rs (stigmal vein), dorsal view, female holotype (OSUC 266165) I I 0 Paridris solaris, sp. n., R1 (postmarginal vein) and r-rs (stigmal vein), dorsal view, female holotype (OSUC 240944) I I I Paridris mystax, sp. n., fore and hind wing, dorsal view, male (OSUC 265200). Scale bars in millimeters.

\section{Acknowledgments}

Thanks to A. Bennett, D.C. Darling, W. Pulawski, K. van Achterberg and M. Sharkey (Thai specimens collected under NSF grant No. DEB-0542864) for the loans of material for this study; to I. Mikó and M. Yoder for generating the appendix of morphological terms; and to L. Musetti, J. Cora, and S. Hemly for critical assistance with specimen handling, software, and databasing. This material is based upon work supported in part by the National Science Foundation under grant No. DEB-0614764 to N.F. Johnson and A.D. Austin. 


\section{References}

Bin F (1981) Definition of female antennal clava based on its plate sensilla in Hymenoptera Scelionidae Telenominae. Redia 64: 245-261. ${ }^{42}$

Förster, A (1856) Hymenopterologische Studien. II. Heft. Chalcidae und Proctotrupii. Ernst ter Meer, Aachen, 152 pp. ${ }^{43}$

Kononova SV, Kozlov MA (2008) [Scelionids of the Palearctic (Hymenoptera, Scelionidae). Subfamily Scelioninae.] Tovarishchestvo Nauchnykh Izdanii KMK, Saint Petersburg, 489 pp. ${ }^{44}$

Kononova SV, Petrov S (2000) [A review of the genera Triteleia, Paridris and Calotelea (Hymenoptera, Scelionidae, Scelioninae) of Palaearctic region.] Vestnik Zoologii 34: 27-35. ${ }^{45}$

Kozlov MA (1976) [A new genus of Scelionidae (Hymenoptera, Proctotrupoidea) from the Far East.] Trudy Zoologicheskogo Instituta Akademii Nauk SSSR 67:97-99. ${ }^{46}$

Kozlov MA, Kononova SV (1985) [New Palearctic genera of scelionids (Hymenoptera, Scelionidae) of the fauna of the USSR.] Vestnik Zoologii 1985(4):36-40. ${ }^{47}$

Kozlov MA, Kononova SV (1990) [Scelioninae of the Fauna of the USSR (Hymenoptera, Scelionidae, Scelioninae).] Nauka, Leningrad, 344 pp. ${ }^{48}$

Lê X-H (2000) Egg-parasites of family Scelionidae (Hymenoptera). Fauna of Vietnam, vol. 3. Science and Technics Publishing House, Hanoi, 386 pp. ${ }^{49}$

Mani MS, Sharma SK (1982) Proctotrupoidea (Hymenoptera) from India. A review. Oriental Insects 16:135-258. ${ }^{50}$

Masner L (1976) Revisionary notes and keys to world genera of Scelionidae (Hymenoptera: Proctotrupoidea)._Memoirs of the Entomological Society of Canada 97:1-87. ${ }^{51}$

Masner L (1980) Key to genera of Scelionidae of the Holarctic region, with descriptions of new genera and species (Hymenoptera: Proctotrupoidea). Memoirs of the Entomological Society of Canada 113:1-54. ${ }^{52}$

Masner L, Muesebeck CFW (1968) The types of Proctotrupoidea (Hymenoptera) in the United States National Museum. Bulletin of the United States National Museum 270: 1-143.53

Mason WRM (1986) Standard drawing conventions and definitions for venational and other features of wings of Hymenoptera. Proceedings of the Entomological Society of Washington $88: 1-7 .{ }^{54}$

Mikó I, Vilhelmsen L, Johnson NF, Masner L, Pénzes Z (2007) Skeletomusculature of Scelionidae (Hymenoptera: Platygastroidea): head and mesosoma. Zootaxa 1571:1-78. ${ }^{55}$

Mineo G (2005) New scelionid wasps from Italy (Hymenoptera). Scelionidae (Hymenoptera) $1: 17-32 .{ }^{56}$

Polaszek A, Agosti D, Alonso-Zarazaga M, Beccaloni G, de Place Bjørn P, Bouchet P, Brothers DJ, Earl of Cranbrook, Evenhuis NL, Godfray HCJ, Johnson NF, Krell FT, Lipscomb D, Lyal CHC, Mace GM, Mawatari SF, Miller SE, Minelli A, Morris S, Ng PKL, Patterson DJ, Pyle RL, Robinson N, Rogo L, Taverne J, Thompson FC, van Tol J, Wheeler QD, Wilson EO (2005) A universal register for animal names. Nature 437:477. ${ }^{57}$

Rajmohana K (2006) Studies on Proctotrupoidea and Platygastroidea (Hymenoptera: Insecta) of Kerala. Memoirs of the Zoological Survey of India 21:1-153. ${ }^{58}$ 
Talamas EJ, Masner L, Johnson NF (2011) Revision of the Malagasy genus Trichoteleia Kieffer (Hymenoptera, Platygastroidea, Platygastridae). ZooKeys 80:1-126. ${ }^{59}$

Wheeler, WM (1935) Two new genera of myrmicine ants from Papua and the Philippines. Proceedings of the New England Zoological Club 15:1-9. ${ }^{60}$

Yoder MJ, Mikó I, Seltmann K, Bertone MA, Deans AR (2010) A gross anatomy ontology for Hymenoptera. PLosONE 5(12): e15991 ${ }^{61}$ 


\section{Endnotes}

1 http://biocol.org/urn:lsid:biocol.org:col:1012

2 http://biocol.org/urn:lsid:biocol.org:col:35284

3 http://biocol.org/urn:lsid:biocol.org:col:33578

4 http://biocol.org/urn:lsid:biocol.org:col:1014

5 http://biocol.org/urn:lsid:biocol.org:col:1016

6 http://biocol.org/urn:lsid:biocol.org:col:1017

7 http://biocol.org/urn:lsid:biocol.org:col:34212

8 http://morphbank.net/?id=592382

9 http://morphbank.net/?id=592383

10 http://morphbank.net/?id=592384

11 http://morphbank.net/?id=592385

12 http://morphbank.net/?id=592369

13 http://hol.osu.edu/map-large.html?id=275737

14 http://morphbank.net/?id=592365

15 http://hol.osu.edu/map-large.html?id=273886

16 http://morphbank.net/?id=592344

17 http://hol.osu.edu/map-large.html?id=241281

18 http://morphbank.net/?id=592366

19 http://hol.osu.edu/map-large.html?id=273916

20 http://morphbank.net/?id=592362

21 http://hol.osu.edu/map-large.html?id=241284

22 http://morphbank.net/?id=592379

23 http://hol.osu.edu/map-large.html?id=241282

$24 \mathrm{http} / /$ morphbank.net/?id=592377

25 http://hol.osu.edu/map-large.html?id=243854

26 http://morphbank.net/?id=592370

27 http://hol.osu.edu/map-large.html?id=273890

28 http://morphbank.net/?id=592367

29 http://hol.osu.edu/map-large.html?id=273878

30 http://morphbank.net/?id=592364

31 http://hol.osu.edu/map-large.html?id=273914

32 http://morphbank.net/?id=592363

33 http://hol.osu.edu/map-large.html?id=241280

34 http://morphbank.net/?id=592343

35 http://hol.osu.edu/map-large.html?id=273893

36 http://morphbank.net/?id=592374

37 http://hol.osu.edu/map-large.html?id=273915

38 http://morphbank.net/?id=592375

39 http://hol.osu.edu/map-large.html?id=275741

40 http://morphbank.net/?id=592368

41 http://hol.osu.edu/map-large.html?id=241283 
42
urn:Isid:biosci.ohio-state.edu:osuc_pubs: 131 urn:lsid:biosci.ohio-state.edu:osuc_pubs:330 urn:Isid:biosci.ohio-state.edu:osuc_pubs:22163 urn:lsid:biosci.ohio-state.edu:osuc_pubs:9730 urn:lsid:biosci.ohio-state.edu:osuc_pubs:1501 urn:Isid:biosci.ohio-state.edu:osuc_pubs:968 urn:lsid:biosci.ohio-state.edu:osuc_pubs: 340 urn:lsid:biosci.ohio-state.edu:osuc_pubs:9718 urn:lsid:biosci.ohio-state.edu:osuc_pubs:236 urn:lsid:biosci.ohio-state.edu:osuc_pubs:311 urn:lsid:biosci.ohio-state.edu:osuc_pubs: 474 urn:lsid:biosci.ohio-state.edu:osuc_pubs:312 urn:lsid:biosci.ohio-state.edu:osuc_pubs:7039 http://www.mapress.com/zootaxa/2007f/zt01571p078.pdf urn:lsid:biosci.ohio-state.edu:osuc_pubs:21224 urn:lsid:biosci.ohio-state.edu:osuc_pubs:20959 urn:lsid:biosci.ohio-state.edu:osuc_pubs:21131 urn:Isid:biosci.ohio-state.edu:osuc_pubs:23390 urn:Isid:biosci.ohio-state.edu:osuc_pubs:3440 doi: 10.1371/journal.pone.0015991 http://morphbank.net/?id=592361 http://morphbank.net/?id=592381 http://morphbank.net/?id=592386 http://morphbank.net/?id=592387 http://morphbank.net/?id=592388 http://morphbank.net/?id=592373 http://morphbank.net/?id=592389 http://morphbank.net/?id=592390 http://morphbank.net/?id=592393 http://morphbank.net/?id=592394 http://morphbank.net/?id=592380 http://morphbank.net/?id=592395 http://morphbank.net/?id=592396 http://morphbank.net/?id=592397 http://morphbank.net/?id=592378 http://morphbank.net/?id=592398 http://morphbank.net/?id=592399 http://morphbank.net/?id=592400 http://morphbank.net/?id=592401 


\section{Appendix I}

Abbreviations Label Used in Text Unique Identyfier of HAO class Label Used in Talamas et al. 2011

\begin{tabular}{|c|c|c|c|}
\hline \multirow[t]{5}{*}{ axc } & axillular carina & http://purl.obolibrary.org/obo/HAO_0000161 & \\
\hline & basiconic sensillum & http://purl.obolibrary.org/obo/HAO_0001729 & \\
\hline & body & http://purl.obolibrary.org/obo/HAO_0000182 & \\
\hline & compound eye & http://purl.obolibrary.org/obo/HAO_0000217 & \\
\hline & conjunctiva & http://purl.obolibrary.org/obo/HAO_0000221 & \\
\hline \multirow[t]{8}{*}{ epc } & epomial carina & http://purl.obolibrary.org/obo/HAO_0000307 & $\begin{array}{l}\text { vertical epo- } \\
\text { mial carina }\end{array}$ \\
\hline & felt field & http://purl.obolibrary.org/obo/HAO_0000322 & \\
\hline & femoral groove & http://purl.obolibrary.org/obo/HAO_0000326 & $\begin{array}{l}\text { femoral de- } \\
\text { presssion }\end{array}$ \\
\hline & frons & http://purl.obolibrary.org/obo/HAO_0001044 & \\
\hline & gena & http://purl.obolibrary.org/obo/HAO_0000371 & \\
\hline & horn of T1 & & \\
\hline & inner orbit of compound eye & http://purl.obolibrary.org/obo/HAO_0000419 & \\
\hline & interantennal process & http://purl.obolibrary.org/obo/HAO_0000422 & \\
\hline \multirow[t]{10}{*}{ loc } & lateral ocellus & http://purl.obolibrary.org/obo/HAO_0000481 & \\
\hline & lateral propodeal carina & http://purl.obolibrary.org/obo/HAO_0000486 & \\
\hline & leg & http://purl.obolibrary.org/obo/HAO_0000494 & \\
\hline & mandible & http://purl.obolibrary.org/obo/HAO_0000506 & \\
\hline & median ocellus & http://purl.obolibrary.org/obo/HAO_0000526 & \\
\hline & mesepisternum & http://purl.obolibrary.org/obo/HAO_0000541 & \\
\hline & $\begin{array}{l}\text { mesoscutal suprahumeral } \\
\text { sulcus }\end{array}$ & http://purl.obolibrary.org/obo/HAO_0000570 & \\
\hline & mesoscutellum & http://purl.obolibrary.org/obo/HAO_0000574 & \\
\hline & mesoscutum & http://purl.obolibrary.org/obo/HAO_0000575 & \\
\hline & mesosoma & http://purl.obolibrary.org/obo/HAO_0000576 & \\
\hline \multirow[t]{9}{*}{ mtps } & metapleural sulcus & http://purl.obolibrary.org/obo/HAO_0000614 & \\
\hline & metapleural triangle & http://purl.obolibrary.org/obo/HAO_0000615 & \\
\hline & metapleuron & http://purl.obolibrary.org/obo/HAO_0001869 & \\
\hline & metascutellum & http://purl.obolibrary.org/obo/HAO_0000625 & \\
\hline & metasoma & http://purl.obolibrary.org/obo/HAO_0000626 & \\
\hline & metasomal depression & http://purl.obolibrary.org/obo/HAO_0000627 & \\
\hline & notaulus & http://purl.obolibrary.org/obo/HAO_0000647 & \\
\hline & occipital carina & http://purl.obolibrary.org/obo/HAO_0000653 & \\
\hline & ovipositor & http://purl.obolibrary.org/obo/HAO_0000679 & \\
\hline \multirow[t]{7}{*}{ pcxs } & paracoxal sulcus & http://purl.obolibrary.org/obo/HAO_0000685 & \\
\hline & plica & http://purl.obolibrary.org/obo/HAO_0000735 & \\
\hline & posterior mesepimeral area & http://purl.obolibrary.org/obo/HAO_0000751 & \\
\hline & posterior scutellar sulcus & http://purl.obolibrary.org/obo/HAO_0000757 & \\
\hline & pronotum & http://purl.obolibrary.org/obo/HAO_0000853 & \\
\hline & posterior propodeal projection & http://purl.obolibrary.org/obo/HAO_0000763 & \\
\hline & propodeum & http://purl.obolibrary.org/obo/HAO_0001249 & \\
\hline
\end{tabular}




\begin{tabular}{l|l|l|l}
\hline & S2 & http://purl.obolibrary.org/obo/HAO_0000035 & \\
\hline & scutoscutellar sulcus & http://purl.obolibrary.org/obo/HAO_0000920 & \\
\hline & T2 & http://purl.obolibrary.org/obo/HAO_0001147 & \\
\hline & T3 & http://purl.obolibrary.org/obo/HAO_0001151 & \\
\hline & T6 & http://purl.obolibrary.org/obo/HAO_0001468 & \\
\hline trc & transverse carina on T2 & & \\
\hline tpc & transverse pronotal carina & http://purl.obolibrary.org/obo/HAO_0001031 & $\begin{array}{l}\text { dorsal epomial } \\
\text { carina }\end{array}$ \\
\hline & ventral clypeal margin & http://purl.obolibrary.org/obo/HAO_0001767 & \\
\hline & ventral metapleural area & http://purl.obolibrary.org/obo/HAO_0001062 & \\
\hline & vertex & http://purl.obolibrary.org/obo/HAO_0001077 & \\
\hline
\end{tabular}

\section{Appendix II}

Lucid key to females of the Paridris nephta species group. (doi: 10.3897/zookeys.133.1613.app)

Copyright notice: This dataset is made available under the Open Database License (http://opendatacommons.org/licenses/odbl/1.0/). The Open Database License (ODbL) is a license agreement intended to allow users to freely share, modify, and use this Dataset while maintaining this same freedom for others, provided that the original source and author(s) are credited.

Citation: Talamas EJ, Masner L, Johnson NF (2011) Revision of the Paridris nephta species group (Hymenoptera, Platygastroidea, Platygastridae). ZooKeys 133: 49-92. doi: 10.3897/zookeys.133.1613.app 